\title{
Crack arrest capabilities of AA2024 and AA7175 aluminum alloys under impact loading
}

\author{
Gunasilan Manar ${ }^{\mathrm{a}, \mathrm{b}}$, Patrice Longère ${ }^{\mathrm{a}, 1}$ \\ aUniversité de Toulouse, ISAE-SUPAERO, Institut Clément Ader (ICA CNRS 5312), \\ Toulouse, France \\ ${ }^{b}$ National Defense University of Malaysia, Kuala Lumpur, Malaysia
}

\begin{abstract}
This paper presents the experimental investigation of the crack arrest capability under impact loading of two types of aluminum alloys that are mainly used in the field of aeronautics, viz. AA2024 and AA7175. Using gas launcher, impact tests were carried out on the edge of double notched plates made of the aluminum alloys. A range of impact speeds was applied from $100 \mathrm{~m} \cdot \mathrm{s}^{-1}$ to $230 \mathrm{~m} \cdot \mathrm{s}^{-1}$. The two alloys show different crack arrest capabilities and failure modes under impact loading. Further analysis on fractured surface reveals that the failure occurs under combination of opening Mode I and shearing Mode II for AA2024 and predominant shearing Mode II for AA7175. Nano-indentation tests were done in a zone containing the tip of the crack to measure the micro hardness field of the surface. Under high loading rate there is evidence of adiabatic shear banding formation for AA7175 which leads to premature failure of the material whereas on the other hand there is no evidence of adiabatic shear band on AA2024.
\end{abstract}

Keywords: Aluminum alloy, Fracture, Impact, Crack arrest; Failure analysis

\section{Introduction}

In the design of aeronautical structures, the damage tolerance study takes an important part. According to Federal Aviation Requirement (FAR) and Joint Aviation Requirement (JAR), the aim of damage tolerance is to reduce the effect of failure due to manufacturing defects and service-induced damage that can cause cracks. Damage tolerance is defined as sustainability of structures weakened by defects until the repairing process takes place. In this context, we are here interested in experimentally investigating the crack arrest capability of aeronautical structural materials, viz. AA2024 and AA7175 aluminum alloys, under dynamic overloading as notably encountered during incidents like bird strike, bird ingestion, hail storm, tools fell down during repairing and maintenance process, etc. Crack arrest is indeed of major interest in order to assess the serviceability of crack-containing structures.

In their pioneering works, Kalthoff and Winkler [1] have experimentally studied the failure of impacted double notched plates made of high strength (maraging and $\mathrm{Cr}-\mathrm{Mo}$ ) steels. Depending on the impact speed magnitude and notch dimensions, cracks initiating from the notch tips propagate either at an angle close to $70^{\circ}$ wrt the notch direction (low speed, blunt notches, tension mode) or in the direction of the notch direction (high speed, sharp notches, shear mode), see Fig.1. Kalthoff and Bürgel [2] have carried out the same experiments on double notched plates made of high strength Cr-Mo steel and AA7075 aluminum alloy. They evidenced that for the hard steel the crack propagation is controlled by tension mode below a

\footnotetext{
${ }^{1}$ Corresponding author: patrice.longere@isae.fr
} 
critical impact speed and by shear mode above this critical speed - as for the previous work, see above. They however evidenced no critical impact speed for the aluminum alloy which systematically fails under shear mode. This absence of critical impact speed has also been shown by Roux et al. [3] for the ARMOX500T armor steel which is seen to fail under shear mode whatever the impact speed - it is to be noted that the plate geometry and impact conditions used by the authors are slightly different than the ones used by Kalthoff and coworkers. By using single notched plates made of high strength C-300 (maraging) steel, Zhou et al. [4] have shown that when a shear mode-controlled crack arrests inside the structure it may ultimately propagate following an angle with the notch direction, i.e. under tension mode, like in Fig.2. For their experiments with plates made of Ti-6Al-4V titanium alloy, the only failure mode observed is shear. They conclude that the difference in failure mode is more likely due to the material properties than the specimen geometry. Failure under shear mode has also been shown in Longère and Dragon [5] on impacted double notched plates made of Ti-6Al-4V titanium alloy.

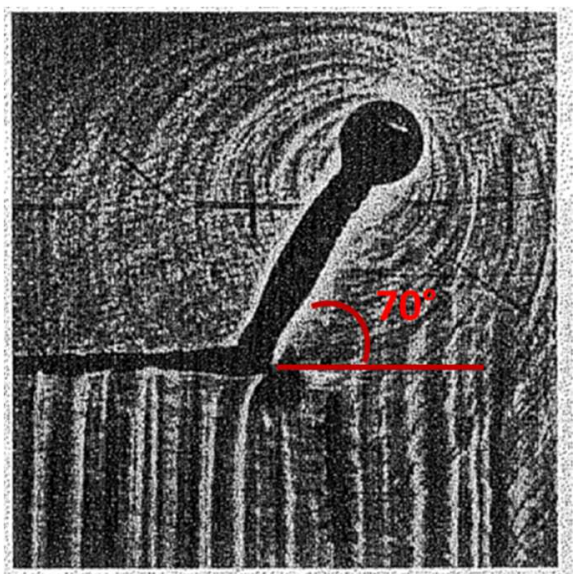

Fig.1 : Mode I-controlled crack propagation along an angle of $70^{\circ}$ wrt notch direction, after [1]

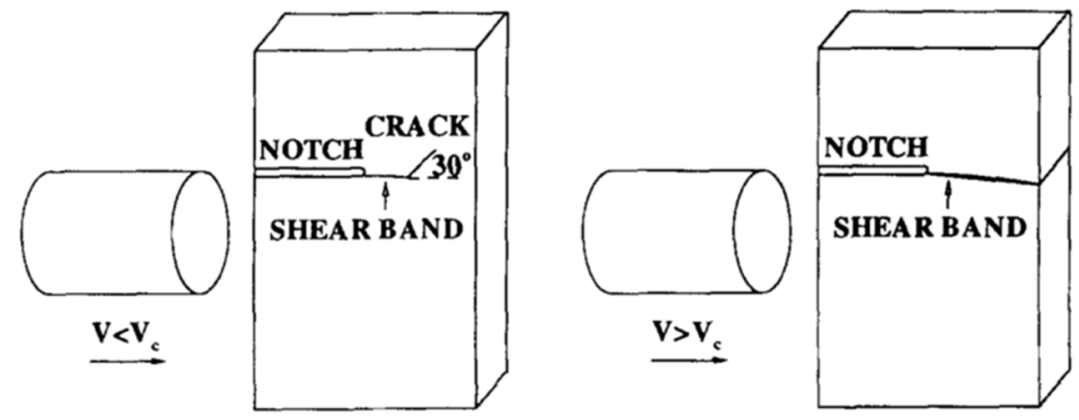

Fig.2 : Asymmetric impact configuration and failure modes, after [4]

Under impact loading, tension mode of failure is commonly associated to brittle-like failure whereas shear mode of failure is generally seen to proceed from shear localization in the form of adiabatic shear bands, see Kalthoff and Winkler [1], Kalthoff and Bürgel [2], Roux et al. [3], and Zhou et al. [4]. Yet, in the work by Longère and Dragon [5] no shear band was observed.

Adiabatic shear banding (ASB) is a shear localization process which develops under high loading rate as the result of the competition between hardening and softening mechanism, see e.g. Bai and Dodd [6]. It is the precursor of the ultimate failure. A review of selected constitutive and numerical models aiming at reproducing the ASB-assisted failure can be found in Longère [7]. Failure under ASB in high strength steels and titanium alloys has been 
evidenced for a long time, see e.g. Zener and Hollomon [8], Dormeval and Ansart [9], Marchand and Duffy [10], Mazeau et al. [11], Liao and Duffy [12]. Evidence of failure under ASB of aluminum alloys seems more recent. For example, Gao et al. [13] and Liang et al.[14] have shown that impacted structures made of AA2519 aluminum alloys may fail under ASB. On the other hand, Yang et al. [15], [16] and Mondal et al. [17] have evidenced ASB as responsible for the failure of impacted structures made of AA7075 aluminum alloys.

The present work aims at experimentally investigating the crack arrest capability under impact loading of two types of aluminum alloys that are mainly used in the field of aeronautics, viz. AA2024 and AA7175. To that purpose, impact tests were carried out using gas launcher on the edge of double notched plates made of the aluminum alloys. A range of impact speeds was applied between $100 \mathrm{~m} \cdot \mathrm{s}^{-1}$ and $230 \mathrm{~m} . \mathrm{s}^{-1}$. The fractured surfaces were observed using optical and scanning electron (SEM) microscopy in view of determining the failure mechanisms. Nano-indentation tests were also carried out in a zone containing the tip of the crack to measure the micro hardness field of the surface in view of evidencing possible microstructural changes. This experimental study allows for comparing the crack arrest capability of the two aluminum alloys under consideration.

The present paper consists of three main parts. Section 2 details the experimental procedure. Section 3 presents the results and analysis which are summarized in Section 4. Section 5 is devoted to the concluding remarks.

\section{Experimental procedure}

In this Section are presented the materials under consideration as well as the experimental and observation devices.

\subsection{Materials under consideration}

Aluminum alloys have been used as primary structures for aircraft since 1930 due to their well-known performance, established manufacturing process and reliable inspection technique. Aluminum alloys also have in particular a good specific strength (strength /weight ratio), see [18] and [19]

AA2000 and AA7000 series of aluminum alloys are two of the most common series used for airframes, with copper as main addition element for the former series (AA2000) and zinc for the latter (AA7000), see Table 1. AA2000 series is generally used in airframe primary structures that require damage tolerance as main criterion whereas AA7000 series is used to sustain high compressive strength and fatigue resistance. Both alloys are recognized for their significant developed strength in the T6 aged condition, however, some of their applications are limited by their relatively low ductility and impact toughness, respectively, as their increase in strength is usually on the expense of their ductility or toughness, see [20].

In the present work two types of aeronautical aluminum alloys will be studied: AA 2024 and AA 7175 aluminum alloys, both in the T351 (temper) thermomechanical state.

From the tension tests which were conducted for both alloys at room temperature and strain rate of $10^{-3} \mathrm{~s}^{-1}$, the yield strength of AA2024 and AA7175 is $342 \mathrm{MPa}$ and $436 \mathrm{MPa}$ respectively. The fracture toughness of AA2024 and AA7175 as reported in literature is 26 $\mathrm{MPa} . \sqrt{\mathrm{m}}$ and $29 \mathrm{MPa} . \sqrt{\mathrm{m}}$, respectively. 


\subsection{Impact tests}

Kalthoff and Winkler (KW) type impact tests, see Kalthoff and Winkler [1], were carried out by using $6 \mathrm{~m}$-length and $40 \mathrm{~mm}$-inner diameter gas launcher tube using STIMPACT impact facility - the facility consists of 3 gas launchers with complementary performances with inner diameter of 40, 60 and $120 \mathrm{~mm}$, respectively, see Figs.3-5 for the experimental setup. The $20 \mathrm{~mm}$-diameter projectile made of hard steel is placed inside a $40 \mathrm{~mm}$-outer diameter cylinder made of foam, see Fig.6, whose function is to reduce the friction inside the gas launcher tube.

Table 1 : Nominal composition of aluminum aerospace alloys[18]

\begin{tabular}{llllllllllll}
\hline Alloy & $\mathrm{Zn}$ & $\mathrm{Mg}$ & $\mathrm{Cu}$ & $\mathrm{Mn}$ & $\mathrm{Cr}$ & $\mathrm{Zr}$ & $\mathrm{Fe}$ & $\mathrm{Si}$ & $\mathrm{Li}$ & $\mathrm{O}$ & Other \\
\hline & & & & & & & & & & & \\
\hline 2004 & - & - & 6.0 & - & - & 0.4 & - & - & - & - & - \\
2014 & - & 0.5 & 4.4 & 0.8 & - & - & $0.7^{*}$ & 0.8 & - & - & - \\
2017 & - & 0.6 & 4.0 & 0.7 & - & - & $0.7^{*}$ & 0.5 & - & - & - \\
2020 & - & - & 4.5 & 0.55 & - & - & $0.4^{*}$ & $0.4^{*}$ & 1.3 & - & $0.25 \mathrm{Cd}$ \\
2024 & - & 1.5 & 4.4 & 0.6 & - & - & $0.5^{*}$ & $0.5^{*}$ & - & - & - \\
7010 & 6.2 & 2.35 & 1.7 & - & - & 0.1 & $0.15^{*}$ & $0.12^{*}$ & - & - & - \\
7049 & 7.7 & 2.45 & 1.6 & - & 0.15 & - & $0.35^{*}$ & $0.25^{*}$ & - & - & - \\
7050 & 6.2 & 2.25 & 2.3 & - & - & 0.1 & $0.15^{*}$ & $0.12^{*}$ & - & - & - \\
7055 & 8.0 & 2.05 & 2.3 & - & - & 0.1 & $0.15^{*}$ & $0.1 *$ & - & - & - \\
7175 & 5.6 & 2.5 & 1.6 & - & 0.23 & - & $0.4^{*}$ & $0.4^{*}$ & - & - & - \\
\hline
\end{tabular}

*Maximum

The target is a 40x82x6 $\mathrm{mm}^{3}$-double notched plate made of the material to test, see Figs.3(c), 4(a) and 5. The $20 \mathrm{~mm}$-length and 300 $\mu \mathrm{m}$-width notches were machined by electric discharge machining (EDM). Lines were engraved on the plate side in view of further digital image analysis, see Roux et al. [3].

The schematic view of the specimen and complete system of data acquisition is shown in Fig.4. Table 2 reports the pressure values and corresponding projectile speeds for $40 \mathrm{~mm}$ inner diameter gas launcher. In the present study, the projectile speed range was from 100 m.s. $\mathrm{s}^{-1}$ until $230 \mathrm{~m} . \mathrm{s}^{-1}$.

The projectile was set to impact the region in between the two notches by using laser alignment method. Laser alignment is a method consisting in directing a laser point from the end of gas launcher tube to the target point on the specimen. The projectile will hit the target at that particular point as set by the laser pointer. The projectile will travel along the tube and its speed will be measured by 2 pairs of photodiodes, 2 emitters and 2 receivers see Fig 5 . As the projectile cuts the photodiodes beam, the changes in the signal recorded by the high data acquisition system allows to determine the speed of the projectile. The signals of the photodiodes were used to trigger the high-speed camera.

\subsection{High-speed frame recording}

A high-speed camera was used to capture the image during the interaction between the projectile and the plate and follow the crack propagation and arrest. 
The Photron SA5 camera was set to capture image at $10^{5}$ frames per second (fps) at 320x192 pixel $^{2}$ spatial resolution. Lighting was provided by Dedolight HMI floodlight with power of $400 \mathrm{~W}$.

The following steps explain the calibration of the distance between two points of the recorded image. For the present explanation, the image was captured at time $0.43942 \mathrm{~s}$. The yellow cursor was placed at the upper part of notch tip and green cursor placed at the beginning of the notch, see Fig.7. The pixel distance for horizontal axis will be the same value which is 0051 . The value for horizontal axis is 0110 for the yellow cursor and 0207 for green cursor. So the differences in the horizontal distance are 97 pixels.
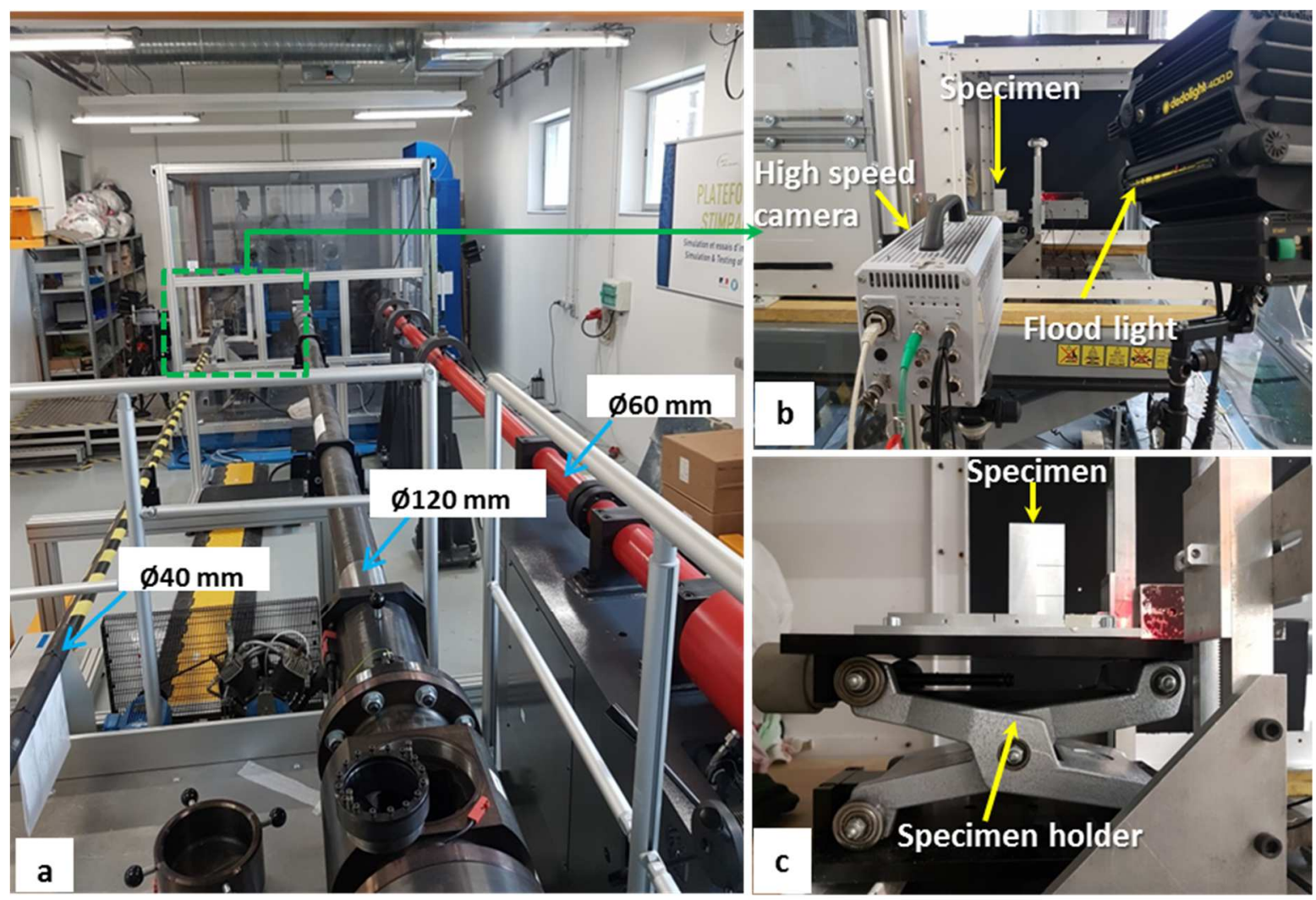

Fig.3 : Impacts tests. (a) STIMPACT facility showing the 3 gas guns; (b) Experimental set up; (c) Specimen and its holder
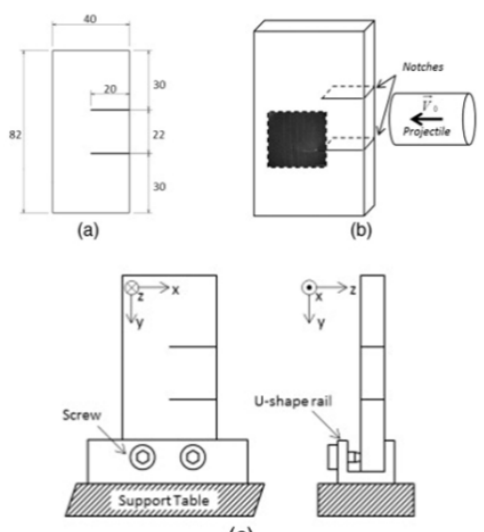

(c)

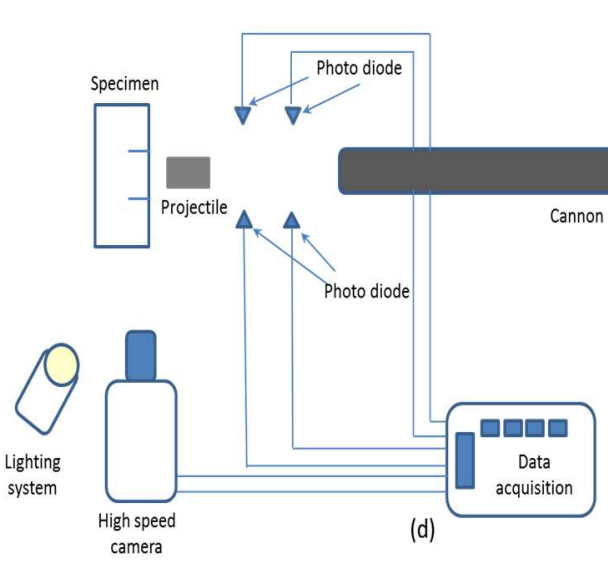

Fig.4 : Schematic view of the impact tests (a) Specimen dimensions (b) Projectile-specimen interaction (c) Plate on its holder [3], (d) Data acquisition system 
Knowing that the length of the notch is $20 \mathrm{~mm}$, the ratio of distance in pixel is converted to millimeter and applied as input value in distance calibration window in Photron software. Once the calibration is done, the distance between any two points in Photron windows can be determined. By applying this technique, the speed of the projectile just before impacting the plate can also be determined.

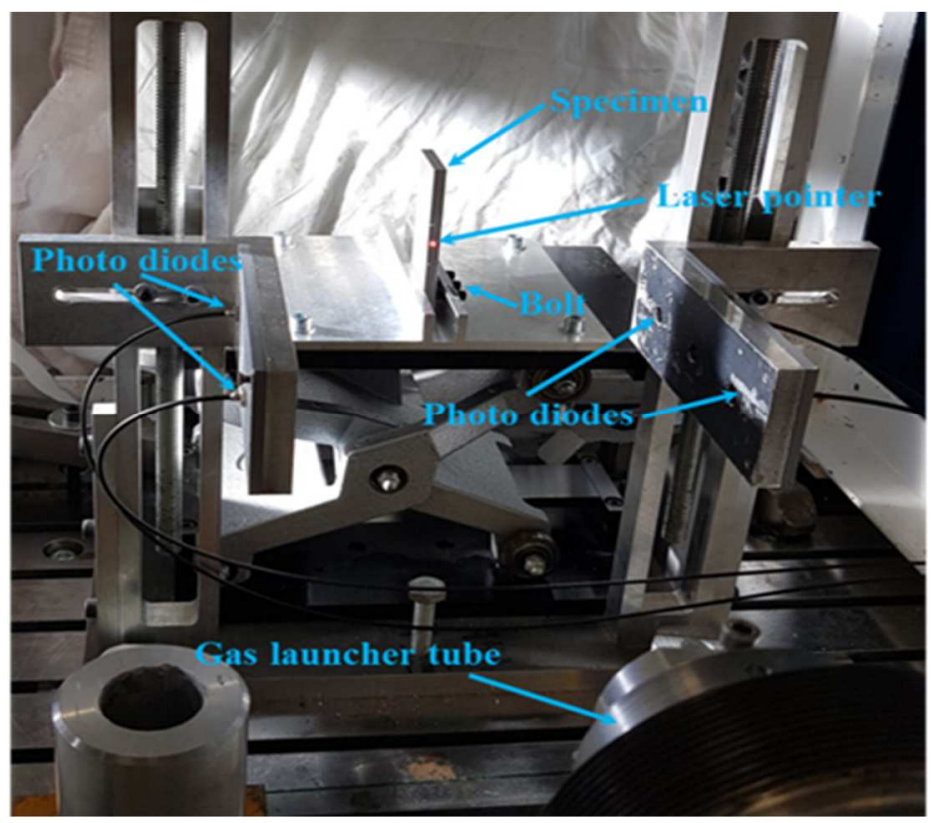

Fig.5 : Specimen alignment and projectile speed measurement

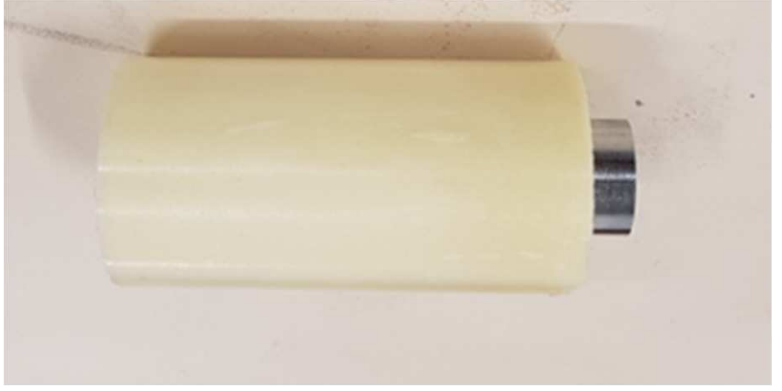

Fig.6 : Steel projectile inside foam housing

Table 2: Pressure and resulting projectile speed for $40 \mathrm{~mm}$-inner diameter gas launcher

\begin{tabular}{ccc}
\hline $\begin{array}{c}\text { Pressure } \\
\text { (bar) }\end{array}$ & $\begin{array}{r}\text { Mass of } \\
\text { projectile and } \\
\text { foam }(\mathrm{g})\end{array}$ & $\begin{array}{r}\text { Projectile } \\
\text { speed }\left(\mathrm{m}_{\mathrm{s}} \mathrm{s}^{-1}\right)\end{array}$ \\
\hline 1.4 & 80.5 & 100 \\
1.5 & 80.5 & 111 \\
1.6 & 80.5 & 120 \\
1.8 & 80.5 & 133 \\
3.0 & 80.5 & 164 \\
9.2 & 80.5 & 230 \\
\hline
\end{tabular}




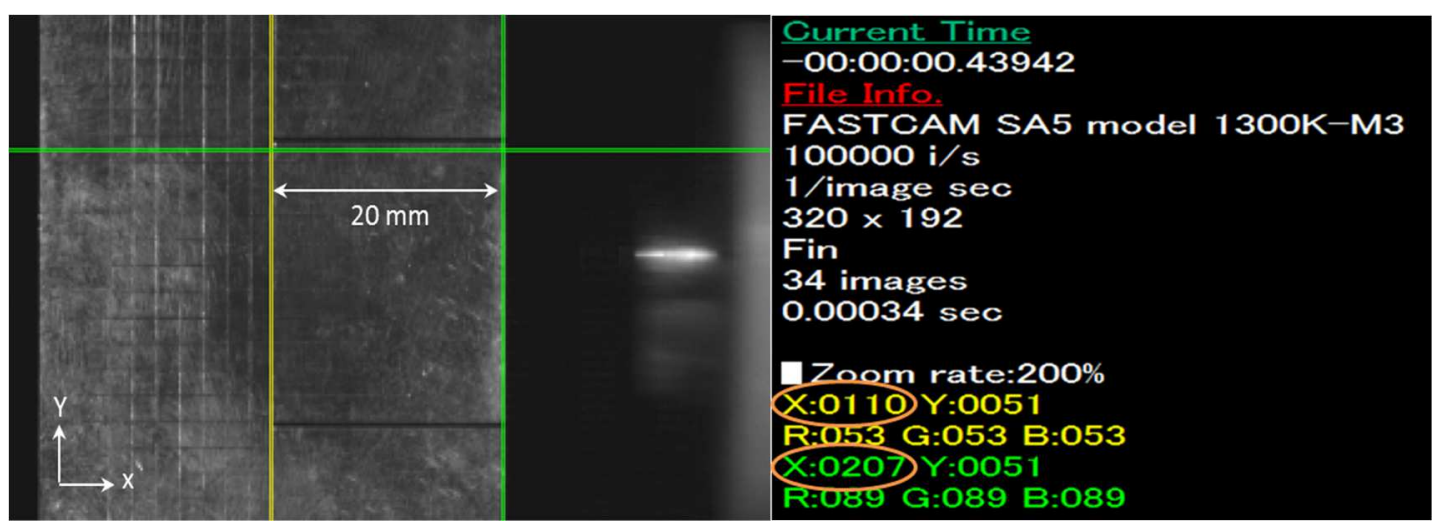

Fig.7 : Distance calibration in Photron software

\subsection{Microscopic examination}

Fractography analyses were performed to observe the micro-mechanisms controlling the crack propagation and arrest.

To that purpose, optical microscope, Olympus GX71, and scanning electron microscope (SEM), Philips XL30ESEM, were used to analyse the specimens after impact. The surface of the fully fractured region was also observed using SEM to investigate the mechanisms that cause failure. For the specimens which were fractured into three parts, the lips of the cracks were observed by using optical microscope in order to identify the existence/absence of band of shear localization.

Microscopic analyses of the specimens were carried out using four different methods. First method (M1) consists in observing without grinding, polishing or etching. Second method (M2) consists in observing after grinding by using sand paper with different successive grain sizes and. Third method (M3) consists in observing after grinding with sand paper and polishing with diamond particle fluids. Fourth method (M4) consists in grinding with sand paper, polishing with diamond particle fluids and etching the specimen. The specimens were etched during 10 to 15 second by acid consisting of $10 \%$ of hydrochloric acid, $10 \%$ of nitric acid, $5 \%$ of hydrofluoric acid and $75 \%$ of water.

\subsection{Nano-indentation test}

Nano-indentation tests were carried out to determine the nano-hardness field around the crack tip in view of identifying potential local microstructural changes.

Fig. 8 shows the nano-indentation apparatus which is available at the Laboratory. The model of this machine is NHT2 and made by CSM Instruments. This model uses compact platform type known as CPX.

Berkovich three sided pyramid type diamond indentor was used to perform the indentation, see Fig.9. A regular map of indentation tests was done around the crack tip. Indentation force is $300 \mathrm{mN}$ and the depth of indent is $2 \mu \mathrm{m} .400$ indentations within the square zone were made for determining the nano-hardness field. Distance between each indentation is $100 \mu \mathrm{m}$. The indentation begins at the tip of crack, covering an area of $2 \times 2 \mathrm{~mm}^{2}$. Indentation hardness given in MPa can be converted into Vickers hardness (HV) as follows

$$
H V=\frac{H(M P a)}{10.8}
$$

where $\mathrm{HV}$ is Vickers hardness and $\mathrm{H}$ is nano-hardness. It is to be noted that the formula given here is an estimate and may be varying according to the type of material. Furthermore nanoindentation and micro-indentation have different indentation depths which may lead to 
different hardness values due to influence of the dislocation, interaction between crystals etc. Nano-indentation is suitable for measure the surface hardness whereas the micro-indentation is suitable for measure the hardness of the bulk material.

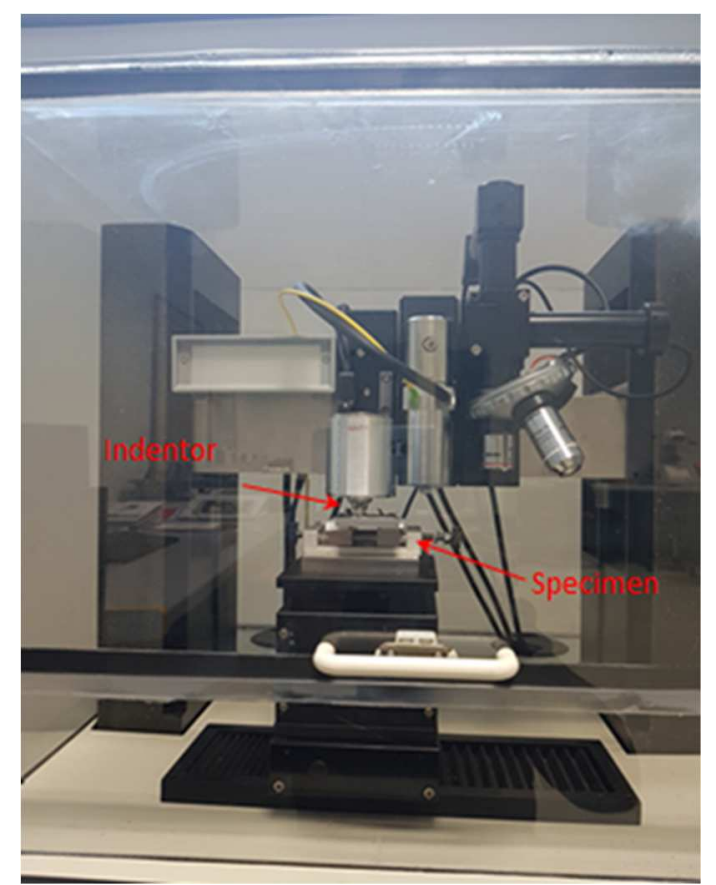

Fig.8 : Nano indentation test apparatus

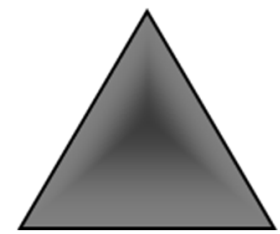

Fig.9: Berkovich three side pyramid-type indentor

The principle of the nano-indentation tests is depicted in Fig.10. The impacted specimen is indented at the tip of the crack over an area of $2 \times 2 \mathrm{~mm}^{2}$. The nano-hardness mapping is obtained from the data analysis and visualization software Gwyddion 2.47.
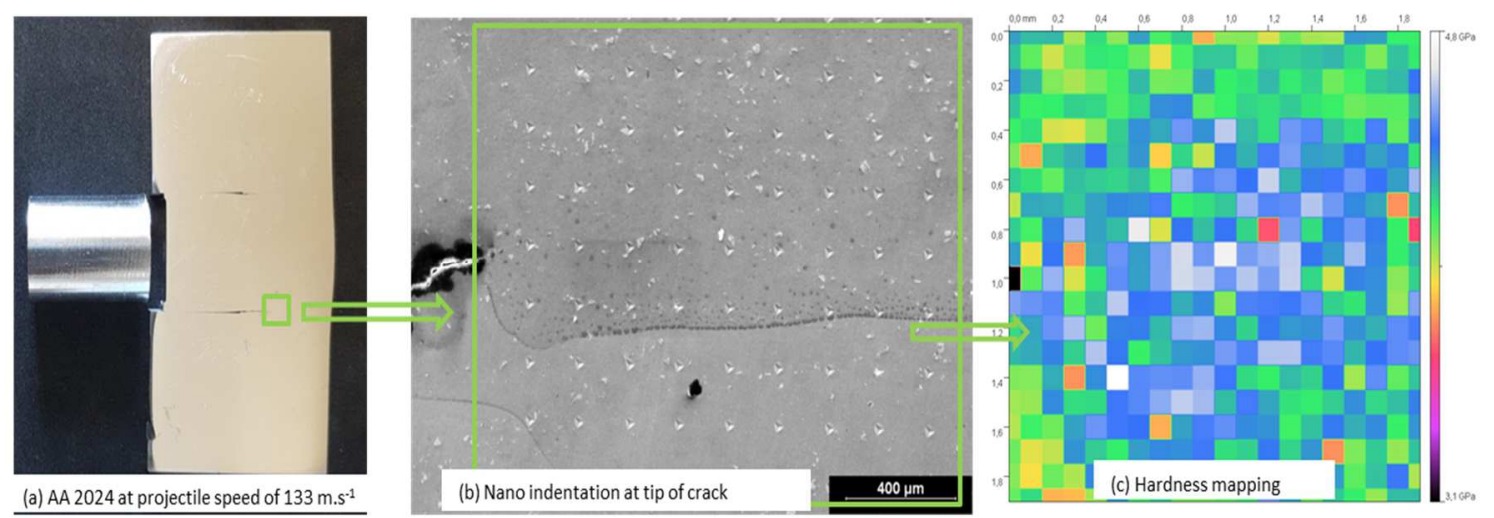

Fig.10 : Principle of the nano-indentation tests in a region containing the crack tip (here for AA 2024 $\left.133 \mathrm{~m} . \mathrm{s}^{-1}\right)$ 


\section{Results and analysis}

The failure analysis is performed in this Section. The chronology of the interaction between the plate and the projectile is in particular discussed.

\subsection{KW impact test results}

The pictures of the post-mortem specimens after different projectile speeds are shown in Fig.11. It is shown that the fracture occurs at different speeds leading to different failure states. The plate ultimately fractures in three parts as the result of the symmetric development of cracks initiated from both notches and propagating in a direction quasi collinear to the notch direction - the fracture of the plate in two parts is probably due to unstable crack propagation which may be magnified by possible slight misalignment between the projectile trajectory and the normal of the plate edge. Each test was carried out once for each configuration

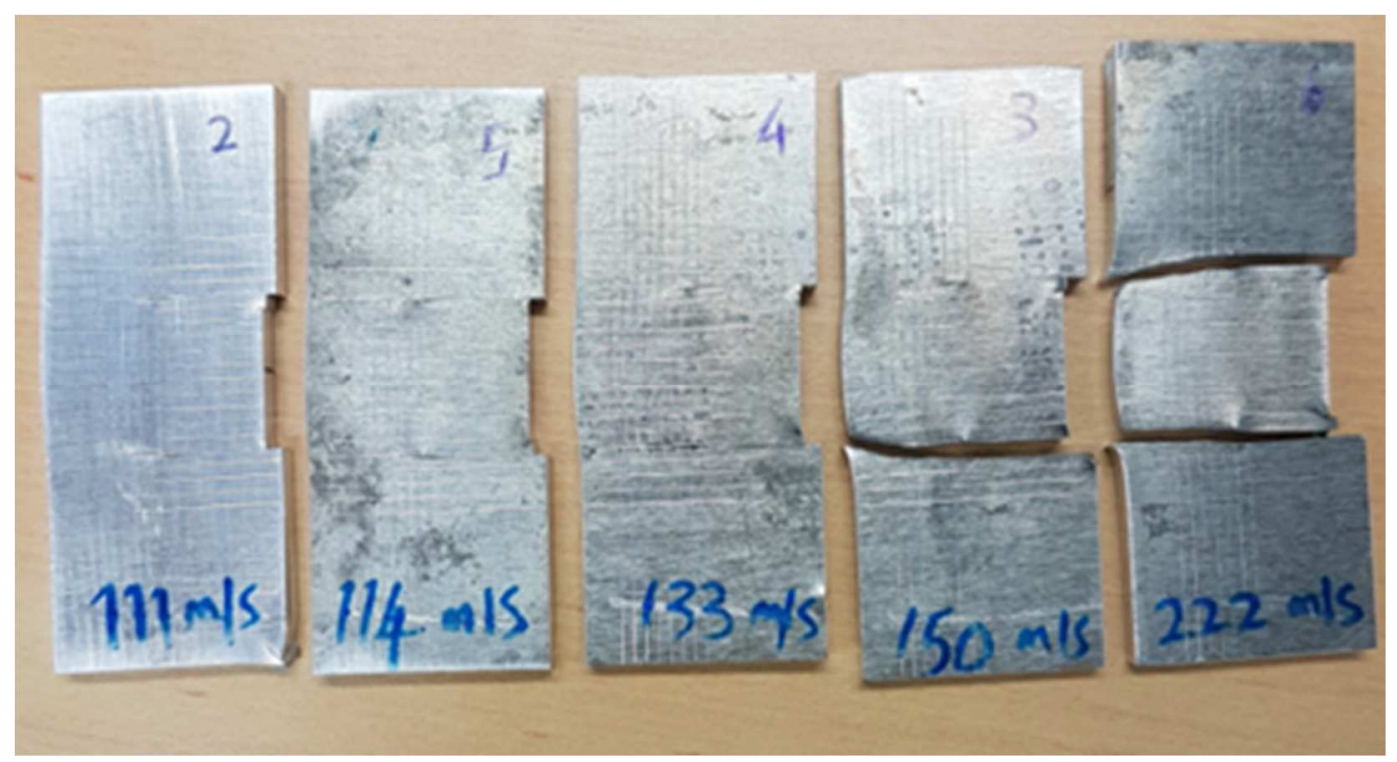

(a) AA 2024

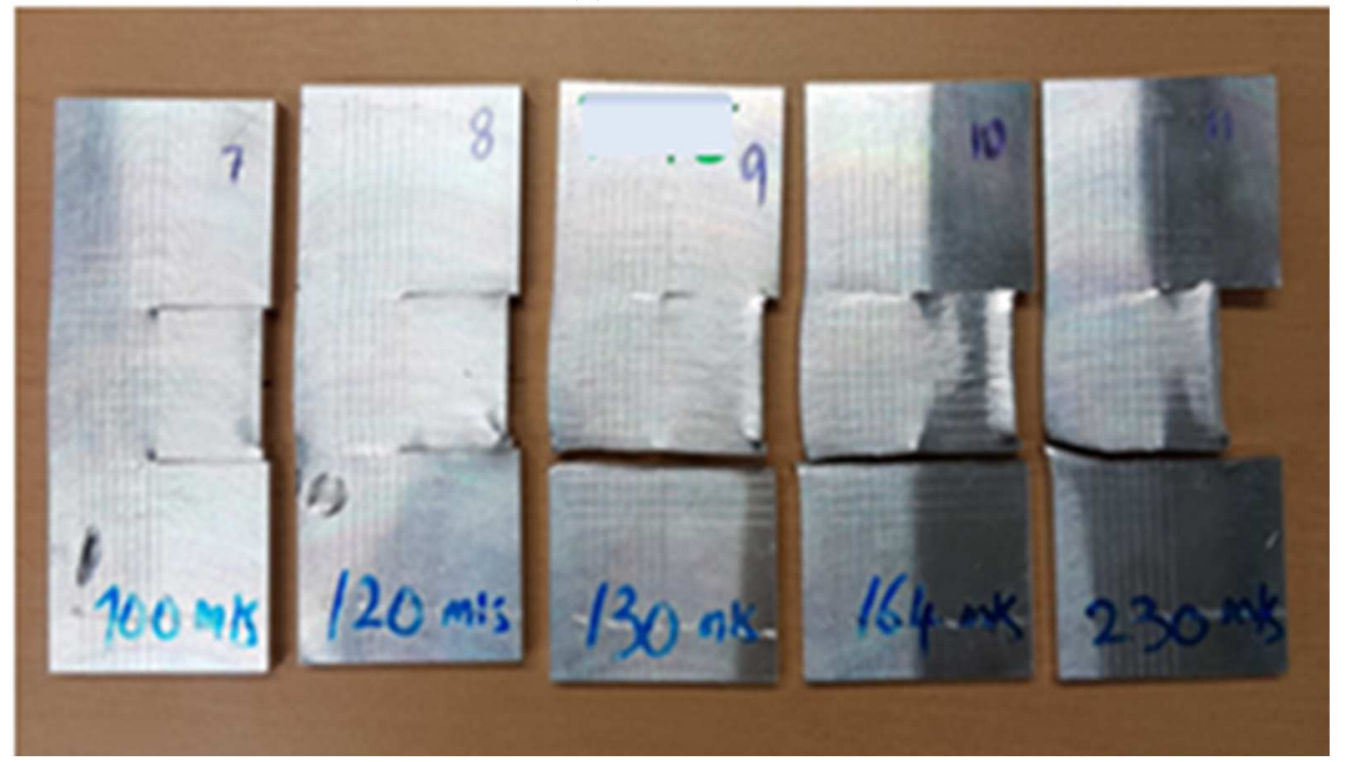

(b) AA 7175

Fig.11 : Post-mortem specimens after impact at various speeds 
For both alloys, the different types of damage involved by the projectile impact speed are reported in Tables 3 and 4 in terms of speed and speed range, respectively. In the range from 100 to $120 \mathrm{~m} . \mathrm{s}^{-1}$, no significant damage is observed for both alloys. For the range of 121 to $140 \mathrm{~m} . \mathrm{s}^{-1}$ AA 7175 is subject to partial fracture. For the range of 141 to $160 \mathrm{~m} \cdot \mathrm{s}^{-1}$ and 161 to $180 \mathrm{~m} . \mathrm{s}^{-1}$ both alloys are subject to partial fracture. For the range of 181 to $230 \mathrm{~m} . \mathrm{s}^{-1}$, AA 2124 was fully fractured at upper and lower notches whereas AA 7175 was only partially fractured.

Table 3 : Failure of specimen at different speeds

\begin{tabular}{|c|r|l|l|l|l|l|l|l|l|l|}
\hline Speed $\left(\mathrm{m} . \mathrm{s}^{-1}\right)$ & 100 & 111 & 114 & 120 & 130 & 133 & 150 & 164 & 222 & 230 \\
\hline AAterial & & & & & & & & & & \\
\hline AA 7175 & & N & N & & & N & PF & & FF & \\
\hline
\end{tabular}

N-No damage PF-Partial Fracture FF- Fully Fracture

Table 4 : Failure of specimen at different ranges of speeds

\begin{tabular}{|c|c|c|c|c|c|}
\hline $\begin{array}{l}\text { Speed range }\left(\mathrm{m} \cdot \mathrm{s}^{-1}\right) \\
\text { Material }\end{array}$ & $100-120$ & $121-140$ & $141-160$ & $161-180$ & $181-230$ \\
\hline AA 2024 & $\mathrm{~N}$ & $\mathrm{~N}$ & $\mathrm{PF}$ & $\mathrm{PF}$ & $\mathrm{FF}$ \\
\hline AA 7175 & $\mathrm{~N}$ & $\mathrm{PF}$ & $\mathrm{PF}$ & $\mathrm{PF}$ & $\overline{\mathrm{PF}}$ \\
\hline
\end{tabular}

N-No damage PF-Partial Fracture...FF-Fully Fracture

For AA2024, at impact speed of $111 \mathrm{~m} . \mathrm{s}^{-1}, 114 \mathrm{~m} \cdot \mathrm{s}^{-1}$ and $133 \mathrm{~m} . \mathrm{s}^{-1}$, the crack arrests inside the structure. From $150 \mathrm{~m} . \mathrm{s}^{-1}$, the specimen is split in two or three parts.

For AA7175 the crack propagates and arrests inside the structure at impact speed of 100 $\mathrm{m} . \mathrm{s}^{-1}$ and $120 \mathrm{~m} \cdot \mathrm{s}^{-1}$. At impact speed of $130 \mathrm{~m} \cdot \mathrm{s}^{-1}$ the plate fully fractures.

The critical impact speed at complete fracture is higher for AA2024 (close to $150 \mathrm{~m} . \mathrm{s}^{-1}$ ) and lower for AA7175 (close to $130 \mathrm{~m} \cdot \mathrm{s}^{-1}$ ).

\subsection{Kinematic analysis of the crack propagation and arrest}

In this Section, an example is presented for low speed where the crack arrests inside the material and for higher speed where the specimen is split into three parts. High-speed frame post-processing was performed to analyze the crack propagation and arrest during the plateprojectile interaction. The speed of the projectile estimated from the frames post-processing is seen to be close to the value measured using the photo diodes, see Fig.5.

The Photron software allows for importing the video of the plate-projectile interaction that was recorded earlier by using Photron high-speed camera. The imported image calibrated by measuring the known distance between two points as explained earlier in the subsection 3.2.3. Once the calibration process is performed, calculations can be done by applying linear equation formula to estimate the speed of the crack tip and ASB propagation.

Due to insufficiently high frame rate and spatial resolution of the camera used, digital image analysis using the lines engraved on the plate side was not possible.

- Low impact speed (< critical impact speed)

The plate-projectile interaction observed through the frames recorded by the high-speed camera at one frame every $10 \mu \mathrm{s}$ can be decomposed into different steps. Examples of chronology are given for AA2024 and AA7175 in Figs.12 and 13 respectively. 


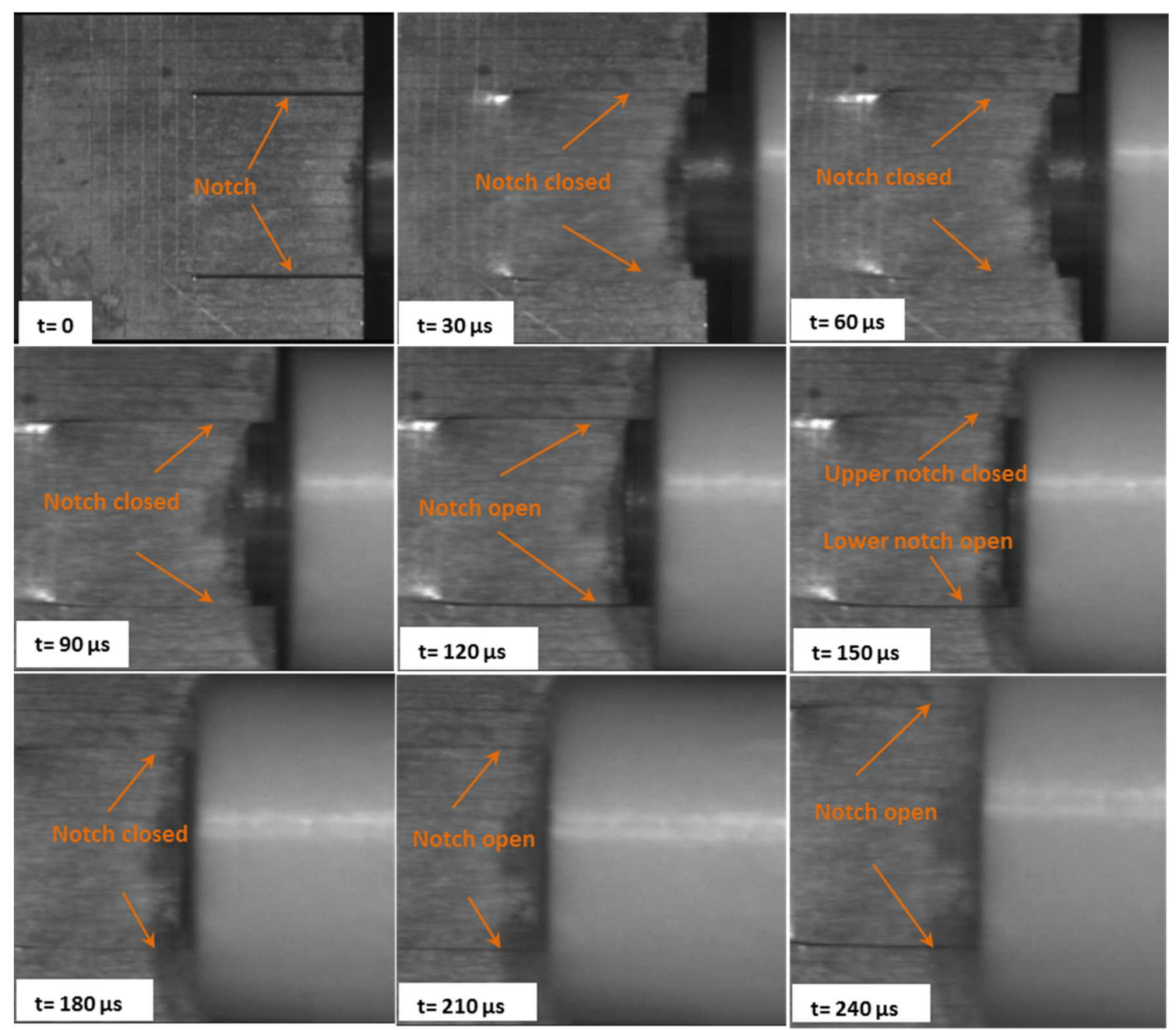

Fig.12 : Kinematics of the plate-specimen interaction. AA2024 - 114 m.s ${ }^{-1}$

According to Fig.3.12 for AA2024,

- between $\mathrm{t}=0$ and $\mathrm{t}=30 \mu \mathrm{s}$ : a compression wave propagates throughout the part of the plate impacted by the projectile leading to the formation of a shear wave at both notch tips; notches are open and cracks initiate symmetrically (i) from the upper part of lower notch tip and (ii) from the lower part of upper notch tip.

- between $\mathrm{t}=30 \mu \mathrm{s}$ and $\mathrm{t}=120 \mu \mathrm{s}$ : due to Poisson-like effect the compression of the part of the plate impacted by the projectile leads progressively to the closure of the gap between notch lips; for the upper notch, the lower lip thus hits the upper lip yielding the propagation of a compression wave in the part of the plate above the upper notch; the compression wave propagates towards the upper free edge of the plate; the symmetric phenomenon occurs for the lower notch; meanwhile, cracks initiated from the notch tips slightly propagate under predominant shear Mode II, i.e. along a direction close to the notch direction.

- between $120 \mu \mathrm{s}$ and $\mathrm{t}=150 \mu \mathrm{s}$ : the gap closure-induced compression waves reflecting from upper and lower free edges of the plate in the form of tension waves cause a re-opening of the gap between notch lips and tension stresses on crack lips; cracks propagate or arrest under combined shear Mode II and opening Mode I.

- beyond $\mathrm{t}=150 \mu \mathrm{s}$ : notches undergo cyclic gap closures and openings as cracks undergo cyclic compression and tension superposed on shear. 


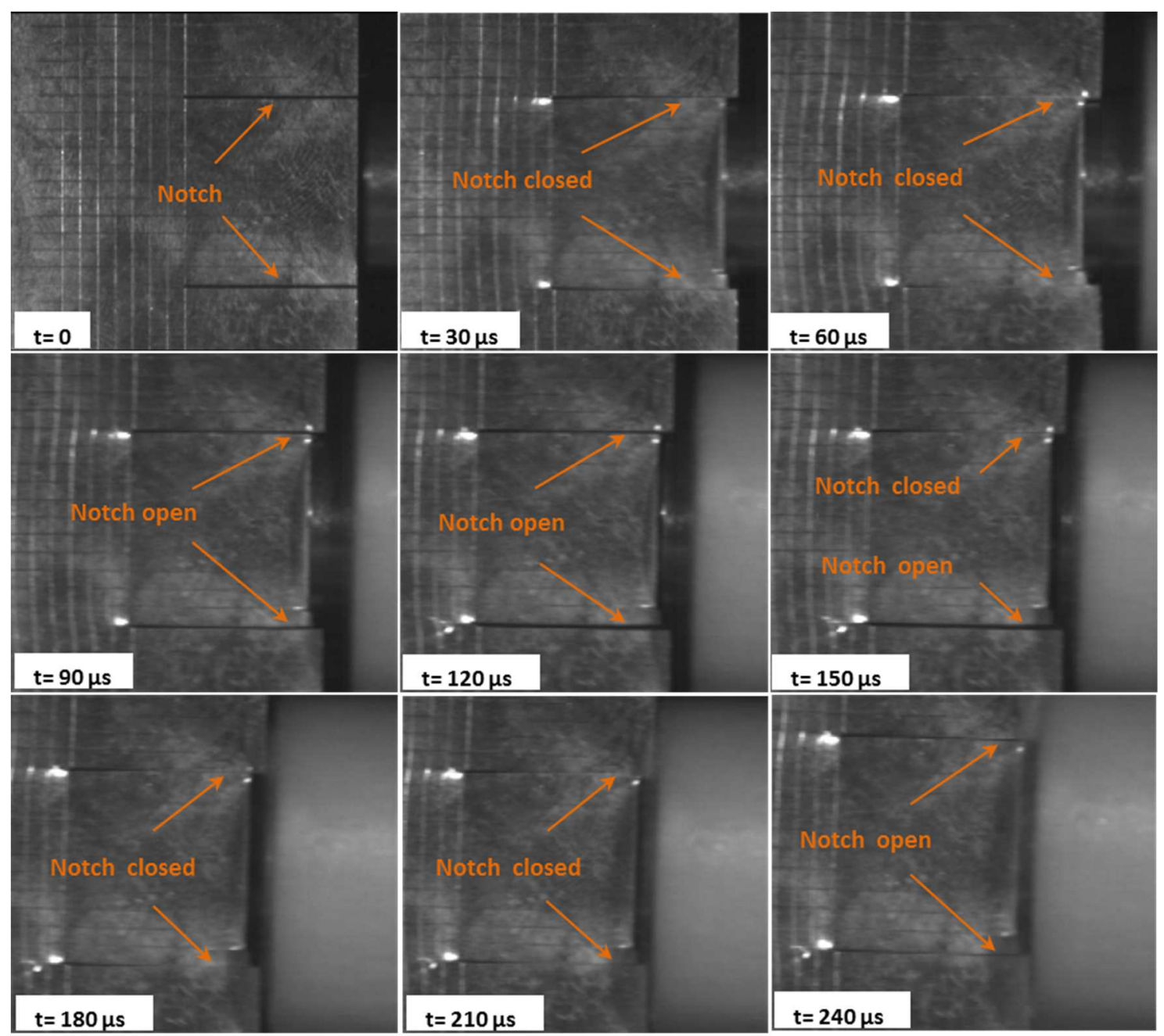

Fig.13 : Kinematics of the plate-specimen interaction. AA7175 - $100 \mathrm{~m} \cdot \mathrm{s}^{-1}$

The same scenario, which is depicted in Fig.14, is observed in Fig.13 for AA7175. Fig.14(a) schematically depicts the projectile and plate before interaction. In Fig.14(b), it is shown that compression wave was generated inside the impacted part of the plate. This compression wave was transformed into a predominant shear wave at the notch tip. Due to Poisson effect-induced gap closure, a compression wave is generated which reflects as tension wave from the free edge of the plate, see Fig.14(c) [5].

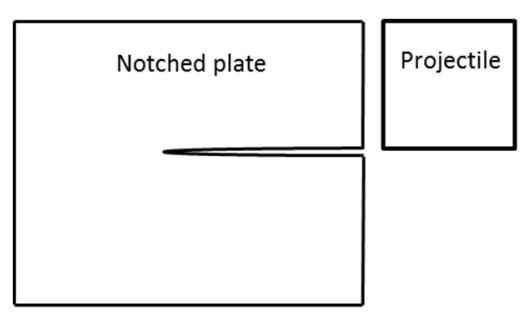

(a)

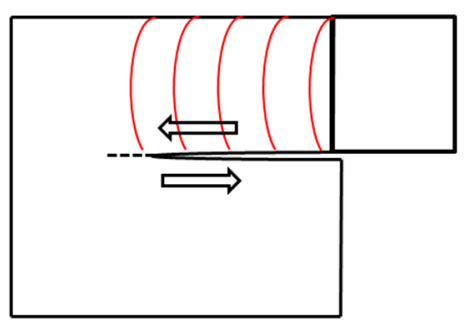

(b)

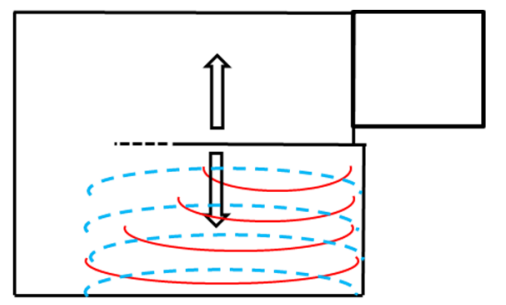

(c)

Compressive wave Tension wave

Fig.14 : Principle of wave interactions. (a) Configuration before impact accounting for symmetry. (b) Compression wave induced in the specimen part impacted by the projectile resulting in shear wave at the notch tip (c) Tension wave resulting from the reflection of the compression wave at the specimen edge. After [5]. 
- High impact speed (> critical impact speed)

For impact speeds greater than the critical impact speed specimens are fully fractured into three parts (or two parts). Considering the lower part of the specimen, further observation can be done.

Fig. 15 depicts the chronology for AA2024 plate at impact speed of $222 \mathrm{~m} . \mathrm{s}^{-1}$ with one frame every $10 \mu \mathrm{s}$. The following steps can be observed:

- between $\mathrm{t}=0$ and $\mathrm{t}=17.4 \mu \mathrm{s}$ : a compression wave propagates throughout the part of the plate impacted by the projectile leading to the formation of a shear wave at the notch tips; the crack initiates.

- between $\mathrm{t}=17.4 \mu \mathrm{s}$ and $\mathrm{t}=37.4 \mu \mathrm{s}$ : due to Poisson-like effect the compression of the part of the plate impacted by the projectile leads progressively to the closure of the gap between notch lips. For the lower notch the upper lip thus hits the lower lip yielding the propagation of a compression wave of the part of the plate above the lower notch; the compression wave propagates towards the lower free edge of the plate.

- between $\mathrm{t}=37.4 \mu \mathrm{s}$ to $\mathrm{t}=47.4 \mu \mathrm{s}$ the crack propagates and measures $6.4 \mathrm{~mm}$

- the crack reaches the length of 16.2 at $\mathrm{t}=57.4 \mu \mathrm{s}$

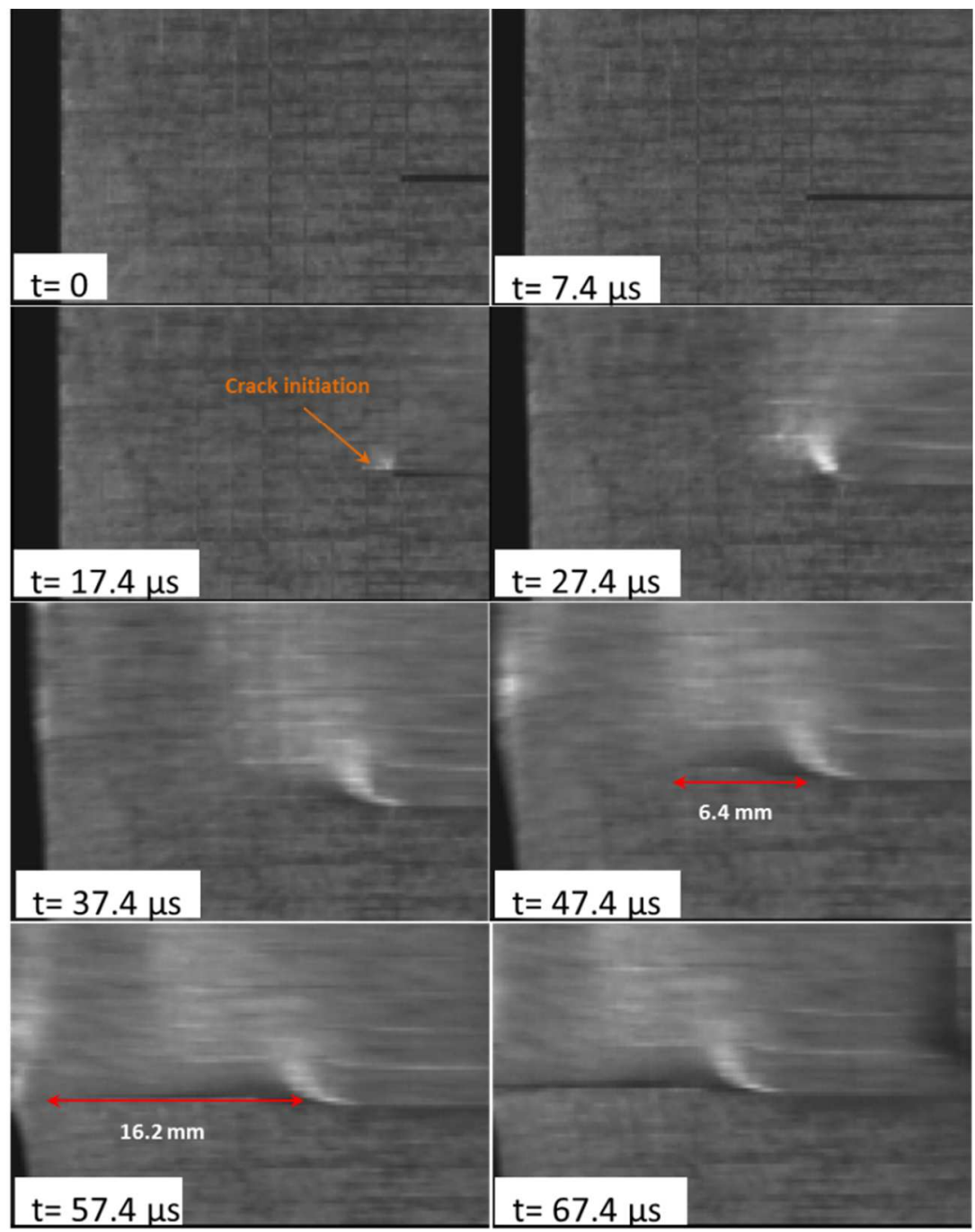

Fig. 15 : Lower part of the AA 2024 plate during impact at $222 \mathrm{~m} \cdot \mathrm{s}^{-1}$ 
An estimate of the crack tip speed value can be done by applying linear motion equation,

$$
\dot{a}=\frac{\Delta a}{\Delta t}
$$

where $\dot{a}, a$ and $t$ are speed, displacement and time respectively.

Fig.16 shows the evolution of crack length and crack tip speed for AA 2024.

- At $\mathrm{t}=47.4 \mu \mathrm{s}$ crack length is $6.4 \mathrm{~mm}$ and at $\mathrm{t}=57.4 \mu \mathrm{s}$ crack length is $16.2 \mathrm{~mm}$.

- At $\mathrm{t}=47.4 \mu \mathrm{s}$ crack tip speed is $640 \mathrm{~m} \cdot \mathrm{s}^{-1}$ and at $\mathrm{t}=57.4 \mu \mathrm{s}$ crack speed is $980 \mathrm{~m} \cdot \mathrm{s}^{-1}$.

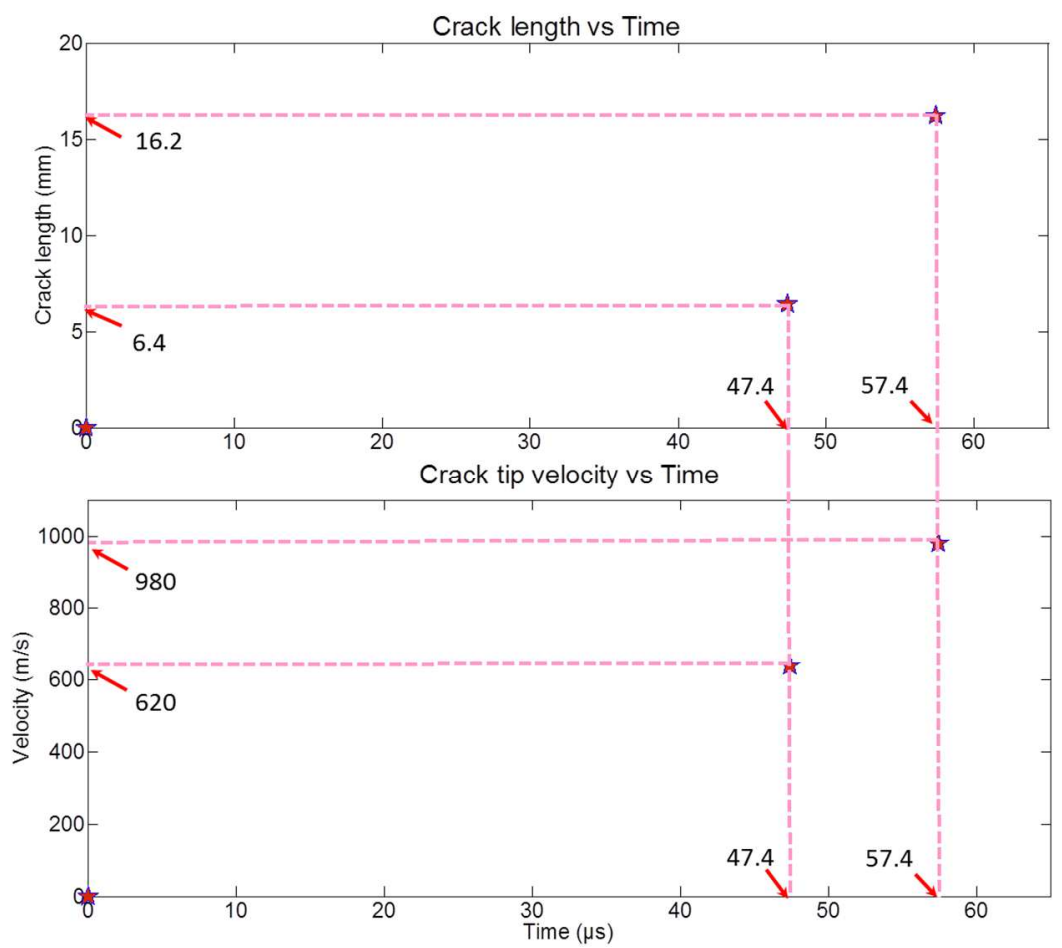

Fig.16 : Crack length and crack tip speed for AA 2024

Fig. 17 depicts the chronology for AA7175 plate at impact speed of $230 \mathrm{~m} . \mathrm{s}^{-1}$ with one frame every $10 \mu \mathrm{s}$. The same observation as discussed for AA 2024 in Fig.15 was observed except for the formation of white band as precursor of the crack and which does not exist for AA 2024.

- At $\mathrm{t}=55.6 \mu \mathrm{s}$ a white band appears at notch tip and propagates about $5.2 \mathrm{~mm}$. This white band further propagates to the left collinearly to the notch direction then with an angle of $15^{\circ}$ upwards.

- the length of this white band is about $12.4 \mathrm{~mm}$ at $\mathrm{t}=65.6 \mu \mathrm{s}$.

- between $\mathrm{t}=75.6 \mu \mathrm{s}$ and $85.6 \mu$ s the crack is indeed propagating but cannot be seen clearly not only due to less resolution but also due to the possible Poisson-like effect where the compression of the part of the plate impacted by the projectile leads progressively to the closure of the gap between notch lips.

The average speed of the white band propagation in AA 7175 for the duration of $10 \mu$ s can be estimated by applying equation 2. Fig.18 shows the white band length and its speed evolutions.

- At $\mathrm{t}=55.6 \mu \mathrm{s}$ the length of white band is $5.2 \mathrm{~mm}$ and the speed of the white band is $520 \mathrm{~m} \cdot \mathrm{s}^{-1}$

- At $\mathrm{t}=65.6 \mu \mathrm{s}$ the length of white band is $7.2 \mathrm{~mm}$ and its speed is $720 \mathrm{~m} . \mathrm{s}^{-1}$ 


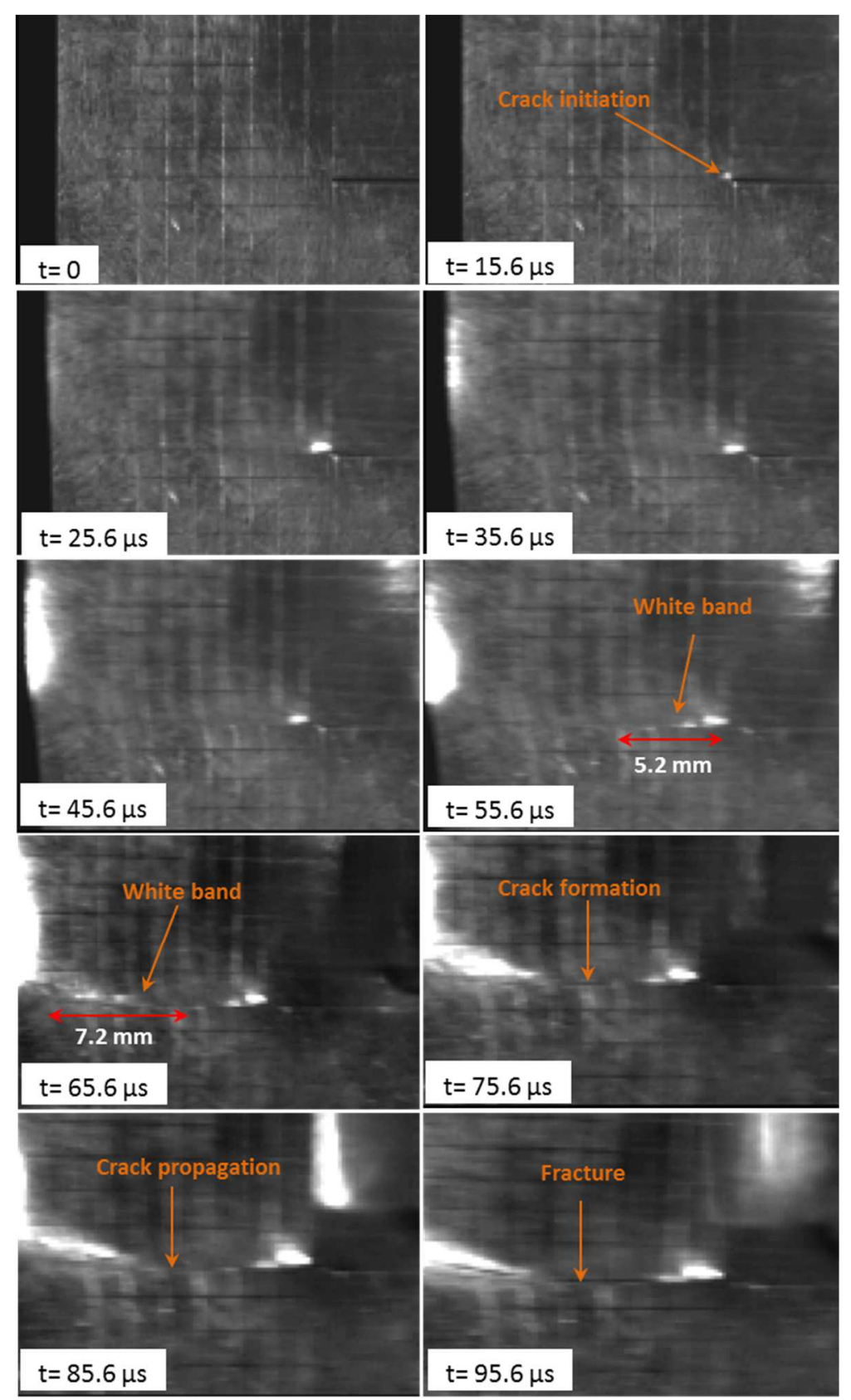

Fig. 17 : Lower part of the AA 7175 plate during impact at $230 \mathrm{~m} . \mathrm{s}^{-1}$

Fig.19 shows the evolution of crack length and crack tip speed:

- at $\mathrm{t}=76 \mu \mathrm{s}$ the crack length is about $6 \mathrm{~mm}$ and its speed is $600 \mathrm{~m} \cdot \mathrm{s}^{-1}$.

- at $\mathrm{t}=86 \mu \mathrm{s}$ is estimated about $800 \mathrm{~m} \cdot \mathrm{s}^{-1}$ respectively.

For comparison, studies by Roux et al. [3] shows that the crack tip speed and white band speed reaches $260 \mathrm{~m} \cdot \mathrm{s}^{-1}$ and $650 \mathrm{~m} \cdot \mathrm{s}^{-1}$ respectively for impact speed of $156 \mathrm{~m} \cdot \mathrm{s}^{-1}$ on high strength ARMOX500T steel plate.

It is reminded that the values of white band and crack speeds, while being approximate, give information allowing for comparing both AA2024 and AA7175. The maximum values of crack speed and white band speed are reported in Table 5. 


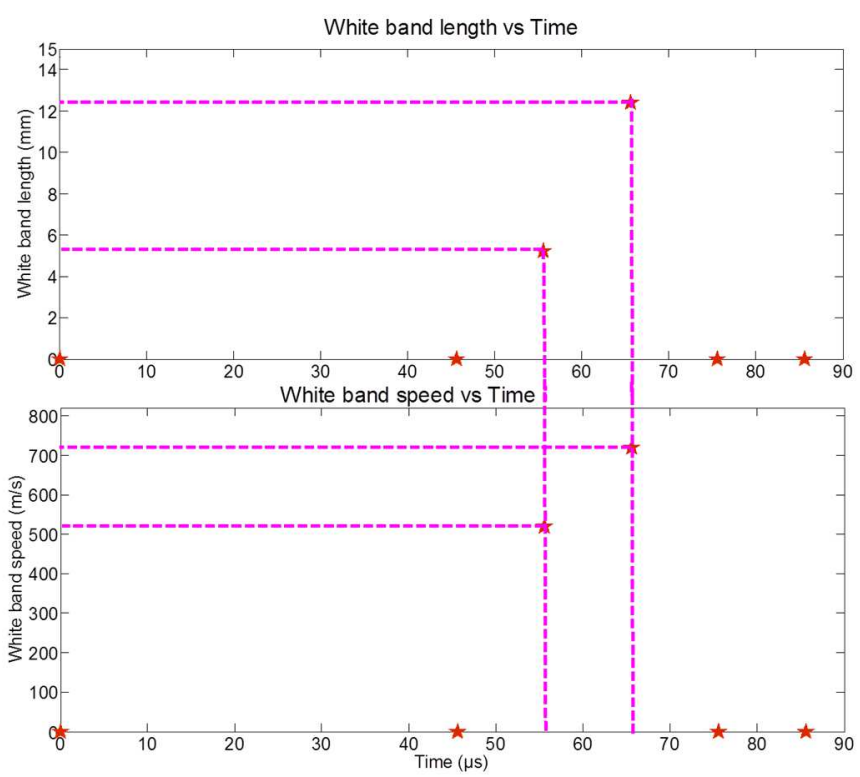

Fig.18 : White band length and white band speed for AA 7175

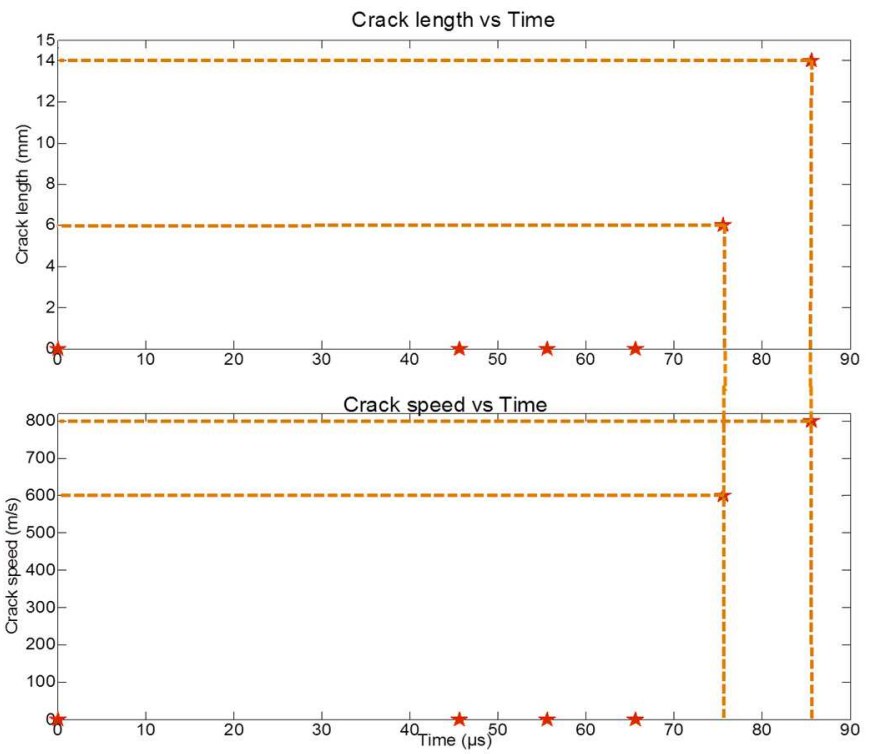

Fig.19 : Crack length and crack speed for AA 7175

From the crack propagation analysis for the specimen at speeds below the critical speed and above critical speed, there are some issues that need to be considered concerning the compressive wave during the impact. The impact of the projectile onto the plate edge will generate a compressive wave which has two effects: first, the transformation of the wave into predominant shear wave at notch tip see Fig.14 (b), and second, the propagation of a tension wave in the direction perpendicular to the impact axis, see Fig.14 (c). According to Longère and Dragon [5], this scenario may repeat several times depending on loading intensity, projectile speed and length. This may explain the crack bifurcation observed in AA7075 by Kalthoff and Bürgel [2], see Fig.11 of the paper [2] and Fig.17 of the present manuscript.

\subsection{Failure analysis of the impacted plates}

In this study fractography analyses were done on four different regions around the cracks: first was on the crack itself, second was inside the crack surface, third was on fully fractured 
surface and fourth was on the lip of the fully fractured surface. Fractography analysis were performed by applying four different condition of specimen based on the requirement. The specimen was analyzed in raw or original condition (M1), grinding with sand paper (M2), grinding with sand paper and polishing with diamond particle fluid (M3) and also etching with acid solution (M4), see subsection 3.2.4. Analysis was done by using optical microscope and SEM.

\subsubsection{Crack propagation analysis}

Crack propagation analysis was done on the specimen after being polished by sand paper and diamond liquid with particle size of $1 \mu \mathrm{m}$ (M2). This is due to the fact that original surface was rough and not suitable for SEM observations. Crack propagation analysis was done on specimen impacted below critical speed where the crack arrests inside the plate. In the following, a 'macro-crack' stands for a crack with open lips whereas a 'meso-crack' stands for a crack with closed lips where matter cohesion remains.

\section{Analysis on AA2024}

The analysis was done on cracks of AA2024 specimens considering two different impact speeds in the speed range considered, see Figs.20 and 21.
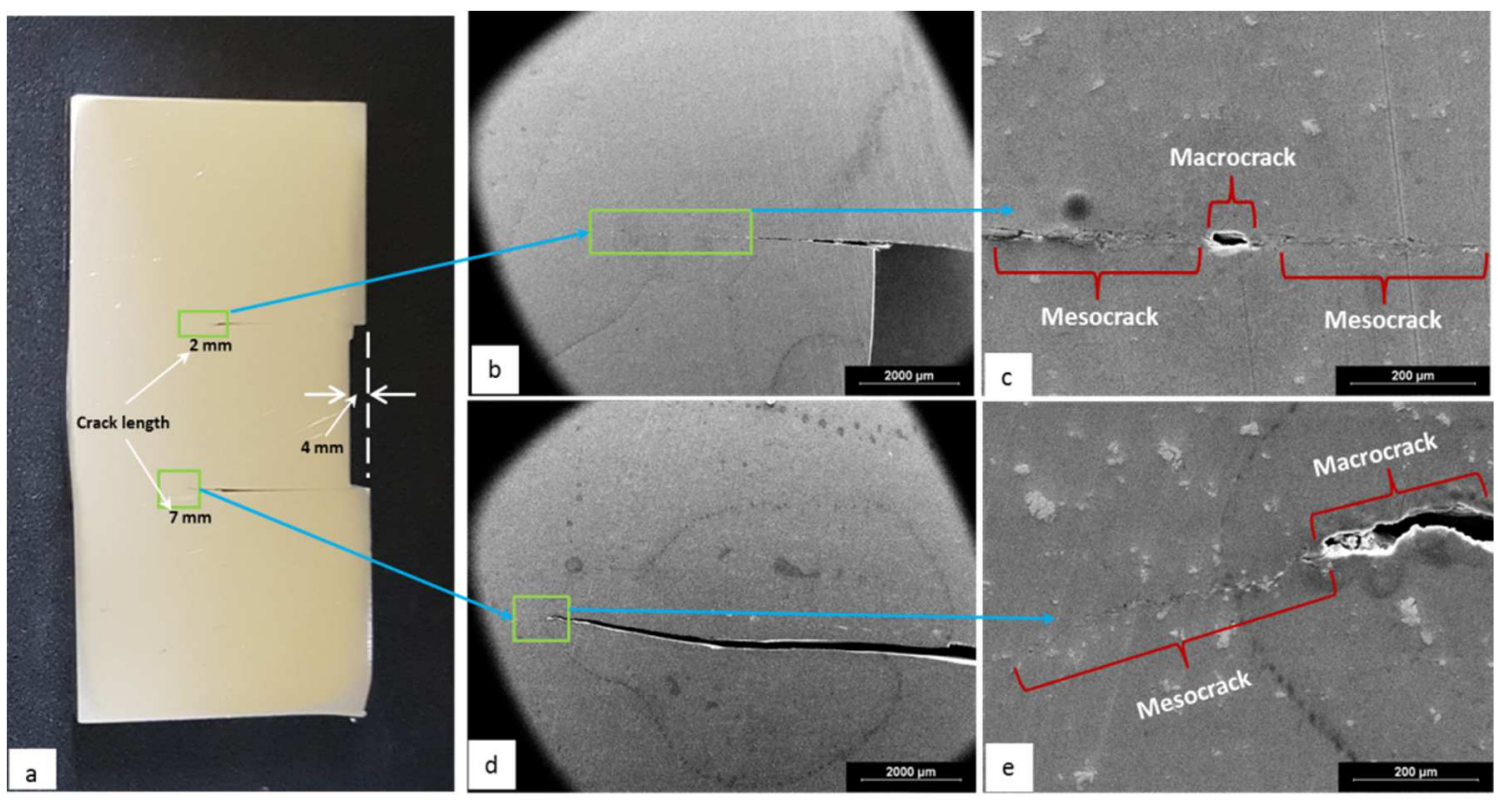

Fig.20 : Post-mortem AA 2024 specimen after impact at 111 m.s ${ }^{-1}$

For impact speed of $111 \mathrm{~m} . \mathrm{s}^{-1}$, lower notch crack is longer than upper notch, see Fig.20 (ac). Lower notch crack length is $7 \mathrm{~mm}$ and upper notch crack length is $2 \mathrm{~mm}$, see Fig.20 (a). The depth of the impacted indentation is about $4 \mathrm{~mm}$, see Fig.20 (a). The cracks are composed of a succession of macro-cracks (in minority) and meso-cracks (in majority), see Fig.20 (c-d).

For impact speed of $133 \mathrm{~m} . \mathrm{s}^{-1}$, upper notch crack and lower notch crack length is $5 \mathrm{~mm}$ and $9 \mathrm{~mm}$ respectively, see Fig. 3.21 (a-c). Impacted indentation depth is $9 \mathrm{~mm}$, see Fig 3.21 (a). The cracks are composed of a succession of macro-cracks (in majority) and meso-cracks (in minority), see Fig.21 (c-d). 


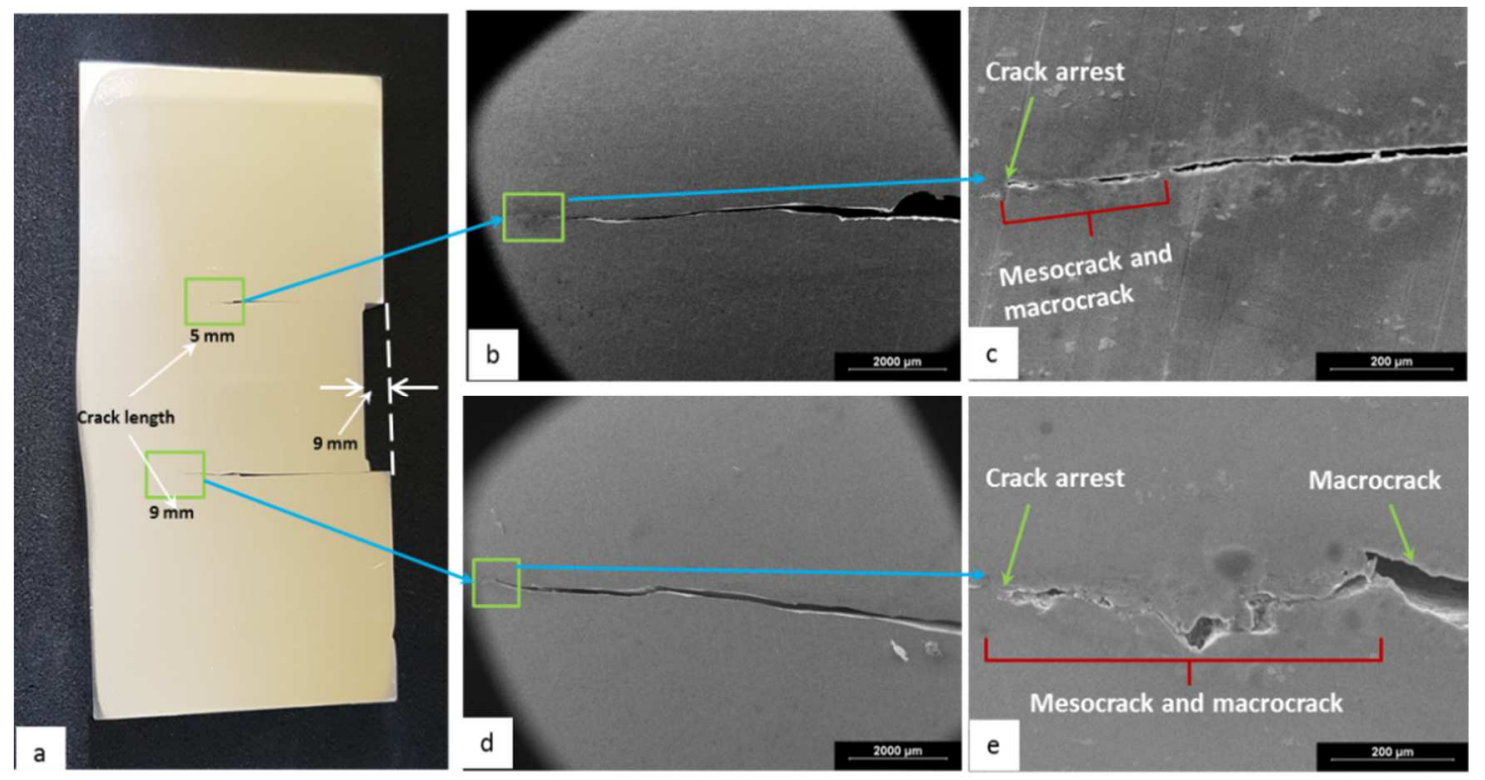

Fig.21 : Post-mortem AA 2024 specimen after impact at $133 \mathrm{~m} . \mathrm{s}^{-1}$

\section{Analysis on AA7175}

Fig.22 shows specimen AA 7175 after impact at speed of $100 \mathrm{~m} \cdot \mathrm{s}^{-1}$. Crack lengths of upper and lower notch are $1 \mathrm{~mm}$ and $4 \mathrm{~mm}$ respectively, see Fig.22 (a). The indentation after impact is 2 mm, see Fig.22 (a). Fig.22 (b) and (c) shows the propagation of the cracks along the notch tip for lower and upper notch respectively. Meso-crack appears along with macrocrack at both notches as shown in Figs.22(c) and (e).
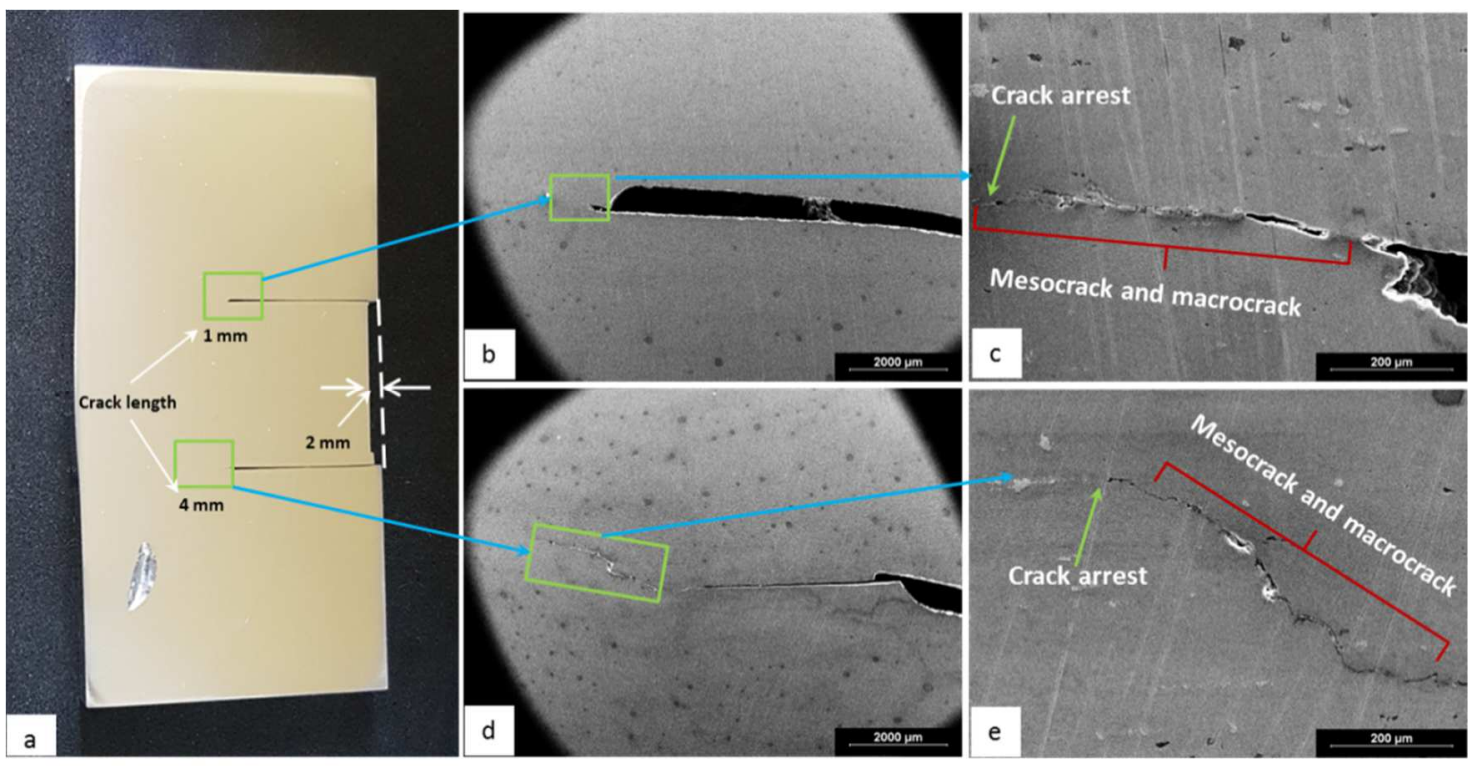

Fig. 22 : Post-mortem AA 7175 specimen after impact at $100 \mathrm{~m} \cdot \mathrm{s}^{-1}$

Fig.23(a) shows the specimen AA 7175 after impact at speed of $120 \mathrm{~m} \cdot \mathrm{s}^{-1}$ with crack length for both upper and lower notches of $2 \mathrm{~mm}$ and $7 \mathrm{~mm}$ respectively. The indentation depth is 3 mm, see Fig.23 (a). Crack propagation is depicted in Fig.23 (b) and (d) for upper and lower notch respectively. There are meso-cracks and macro-cracks appearing in both crack tips, see Fig.23(c) and (e). 

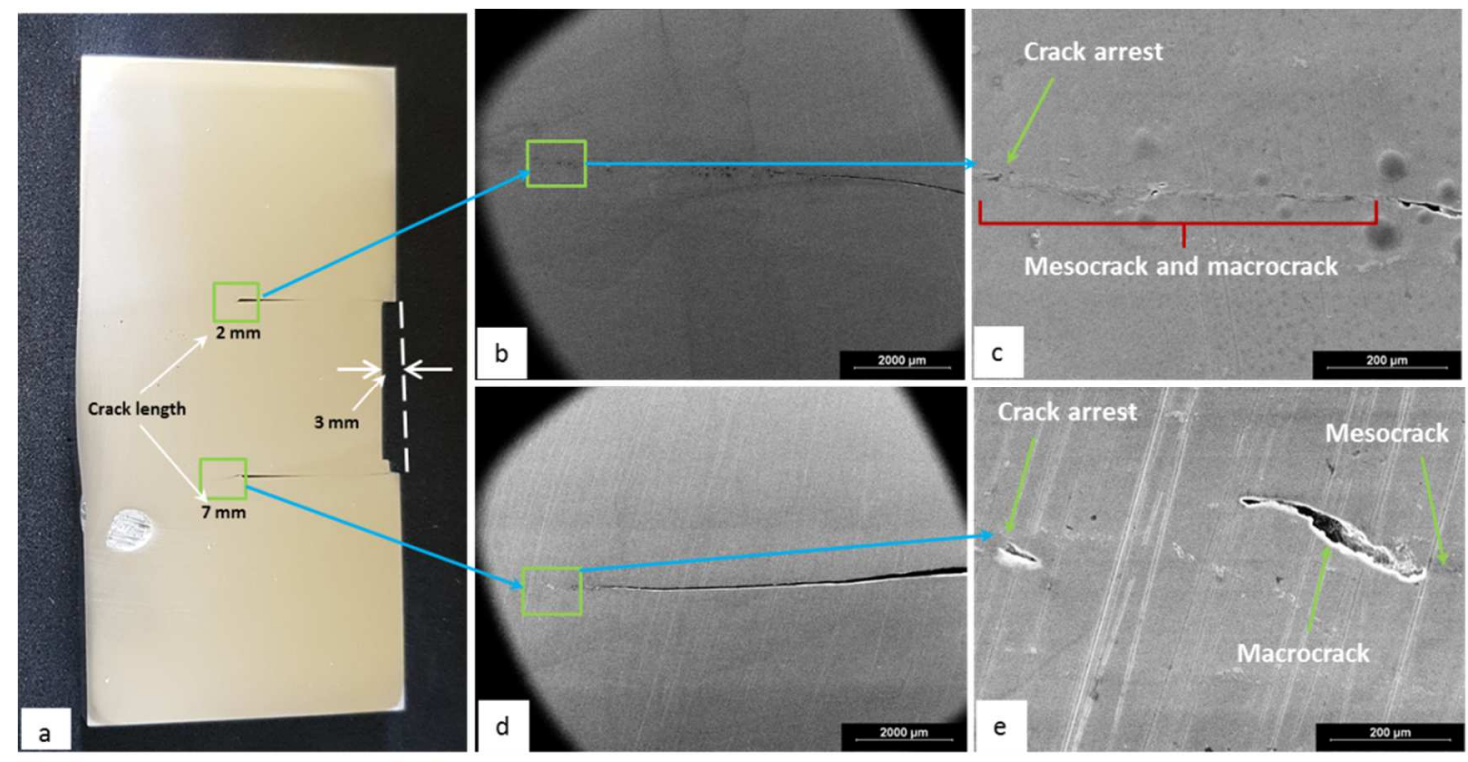

Fig.23 : Post-mortem AA 7175 specimen after impact at $120 \mathrm{~m} . \mathrm{s}^{-1}$

It is expected that macro-cracks develop in the wake of meso-cracks by a progressive opening of the latter. In the present work, the succession of meso- and macro-cracks seems to show that the plate is subject to a complex loading, e.g. a combination of shear and tension loading.

\subsubsection{Internal crack surface analysis}

Specimen used to analyze the surface inside the crack was grinded by sand paper (M2), in order to remove the impurities on the surface and make the surface flat.

\section{Analysis on AA2024}

Fig.24(a) shows the crack propagation for AA2024 KW specimen impacted at speed of $114 \mathrm{~m} \cdot \mathrm{s}^{-1}$. The upper part of the crack was chosen for analyze because of its longer crack length. Total length of crack is about $7 \mathrm{~mm}$.

The crack was analyzed at 3 zones as shown in Fig.24(b). Fig.25 shows the detail of microstructure of the three zones. Image 1, Fig. 25 shows that the initiation of crack from the notch tip is characterized by flat shear and elongated dimples. The beginning of crack propagation proceeds by predominant shear Mode II due to the surface is characterized by flat shear and elongated dimple, see image 2, Fig.25. Image 3, Fig.25 shows crack bifurcation characterized by changes in the loading mode. It is worth noting that the crack bifurcates upwards, i.e. according to clockwise rotation. The microstructure inside the bifurcation zone depicts the combination of flat shear and dimple cluster, as a consequence of the combination of tension loading in opening Mode I and shear loading induced Mode II.

\section{Analysis on AA7175}

Fig.26(a) shows the crack arrest inside the AA7175 specimen for the impact speed of 120 m.s ${ }^{-1}$. Fig.26 (b) shows the macroscopic view of the crack. The total length of the crack is close to $8 \mathrm{~mm}$. 


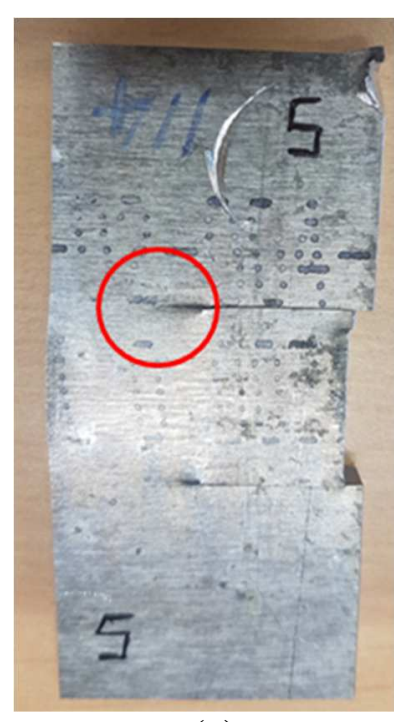

(a)

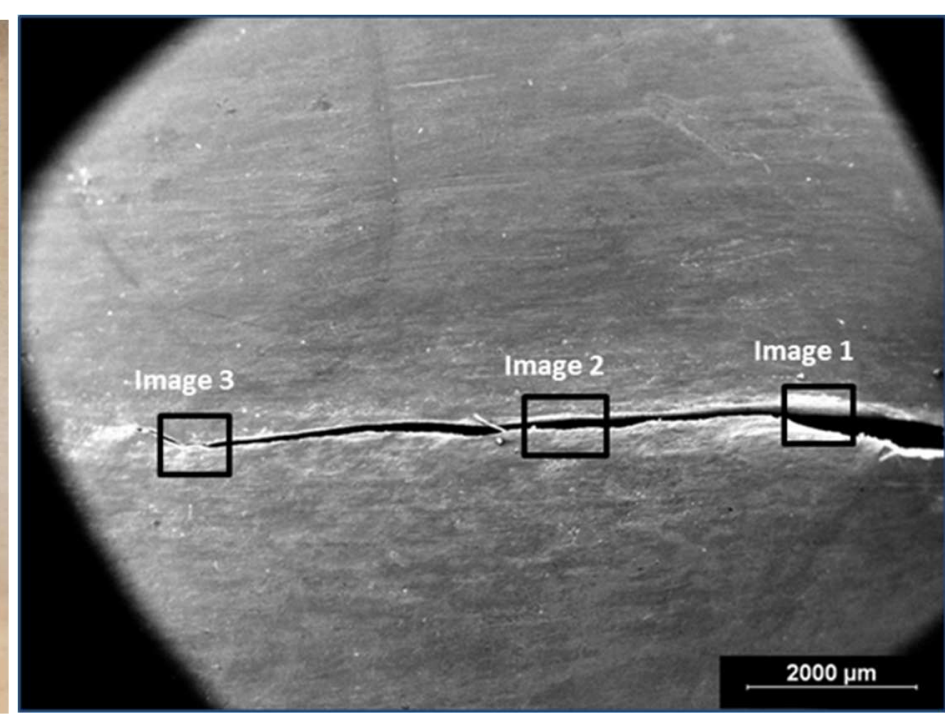

(b)

Fig. 24 : (a) Post impacted AA 2024 double notch plate at $114 \mathrm{~m} . \mathrm{s}^{-1}$ (b) Macroscopic view of crack after surface polishing

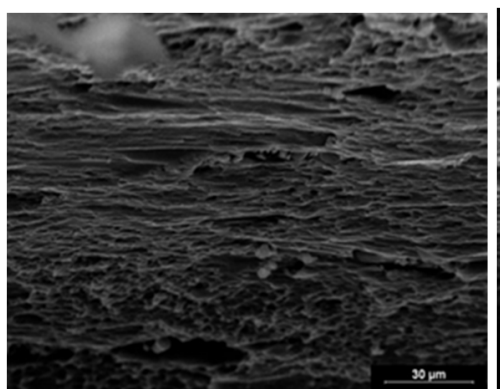

Image 1

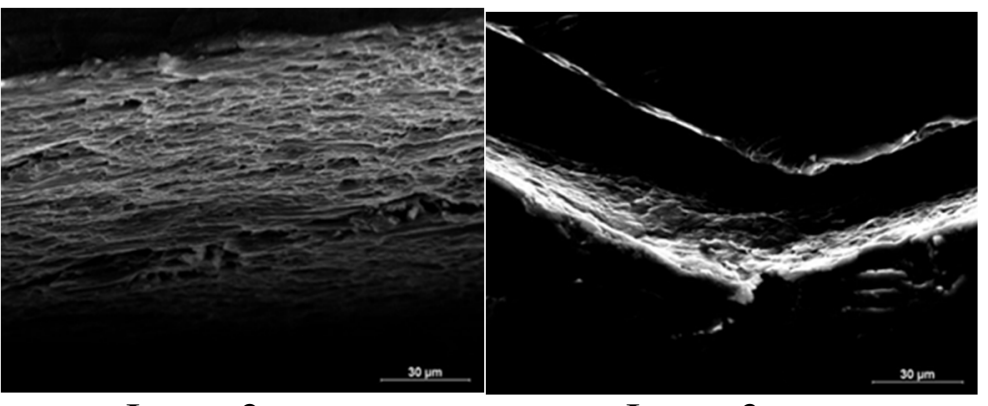

Image 2
Image 3

Fig. 25 : Microstructure of crack for AA 2024 after impact speed of 114 m.s.

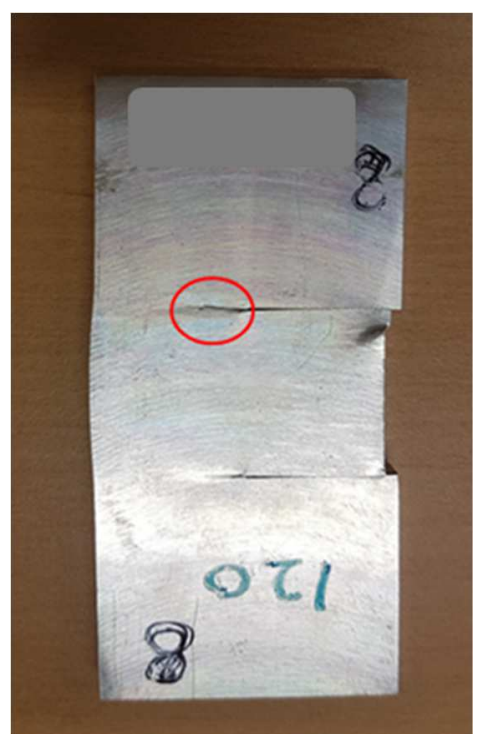

(a)

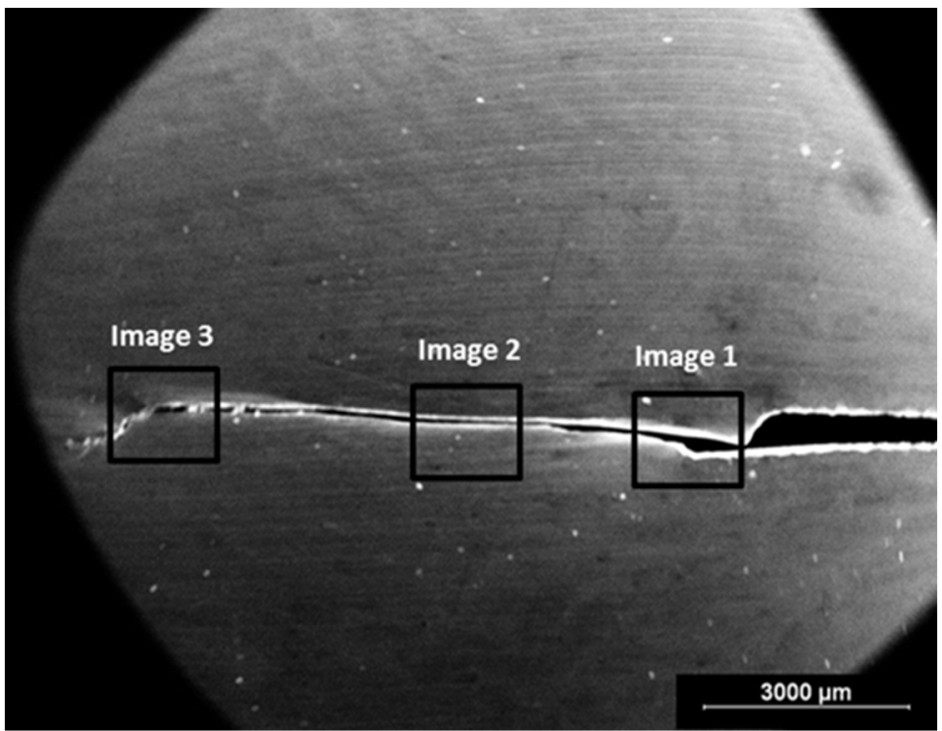

(b)

Fig.26 : (a) Post impacted AA 7175 double notch plate at $120 \mathrm{~m} \cdot \mathrm{s}^{-1}$ (b) Macroscopic view of crack after surface polishing

Fig.27 shows three images of microstructure inside the crack zone at three different locations for AA7175 at impacted speed of $120 \mathrm{~m} . \mathrm{s}^{-1}$. The initiation of the crack from the 
notch tip is characterized by flat shear surface dominated by shearing induced Mode II failure, see image 1, Fig.27. Image 2, Fig.27 reveals that the crack propagation seems to proceed with predominant shearing induced Mode II due to existence of flat shear surface. Image 3, Fig.27 shows the change in loading direction at crack bifurcation zone, where the microstructure is flat shear surface and mode II failure still seems predominant. It is worth noting that the crack bifurcates downwards, i.e. according to anti-clockwise rotation.

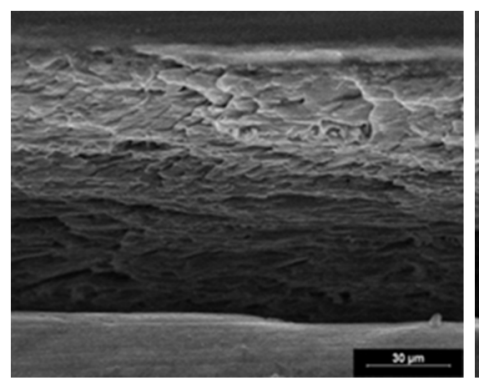

Image 1

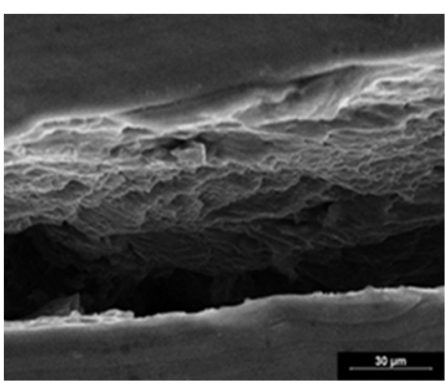

Image 2

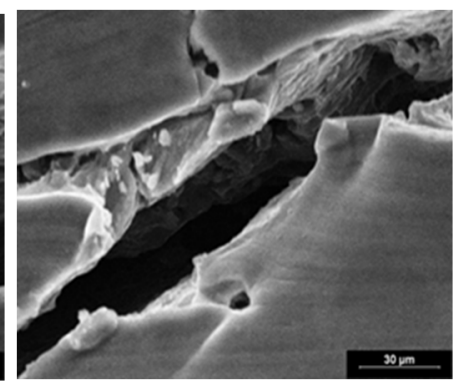

Image 3

Fig. 27 : Microstructure of crack for AA 2024 after impact speed of $114 \mathrm{~m}_{\mathrm{s}} \mathrm{s}^{-1}$

For AA2024, the cracks propagate under shear Mode II then under combined shear Mode II and tension Mode I (bifurcation following clockwise orientation for upper crack).

For AA7175, the cracks seem to propagate under predominant shear Mode II only (bifurcation following anti-clockwise orientation for upper crack), as if the cracks followed a track (done by e.g. the white band evoked in subsection 3.3.2).

\subsubsection{Fully fractured surface analysis}

AA2024 and AA7175 specimens were observed in original condition, (M1). Figs.28(a) and (b) shows the ruptured surface of specimen after being impacted at the speeds of $150 \mathrm{~m} \cdot \mathrm{s}^{-1}$ and $164 \mathrm{~m} . \mathrm{s}^{-1}$ for AA2024 and AA7175 respectively.

\section{Analysis on AA2024}

According to Fig.28(a) for AA2024 two different fracture zones can be seen. Zone 1 shows the surface at crack initiation and zone 2 shows the crack propagation which ultimately leads to full fracture of the specimen.

Fig.29 shows the microstructure of AA2024 for both zones of ruptures after impact at 150 $\mathrm{m} . \mathrm{s}^{-1}$. Microstructural view for AA2024 shows, first zone is flat shear (Mode II) and second zone is opening mode where microstructural view shows a dimple cluster (Mode I) for AA2024.

\section{Analysis on AA7175}

Fig.28(b) also shows two zones where, zone 1 is crack initiation and zone 2 is crack propagation leading to full fracture of the structure. According to image in Fig.28 (b) crack lip area depicts similarity with the crack initiation zone 1 .

Fig.30 shows the microstructure of AA7175 after impact at speed of $164 \mathrm{~m} . \mathrm{s}^{-1}$. Microstructural view of AA7175 shows both region are flat shear surface, thus the failure is mainly due to shear (Mode II). 


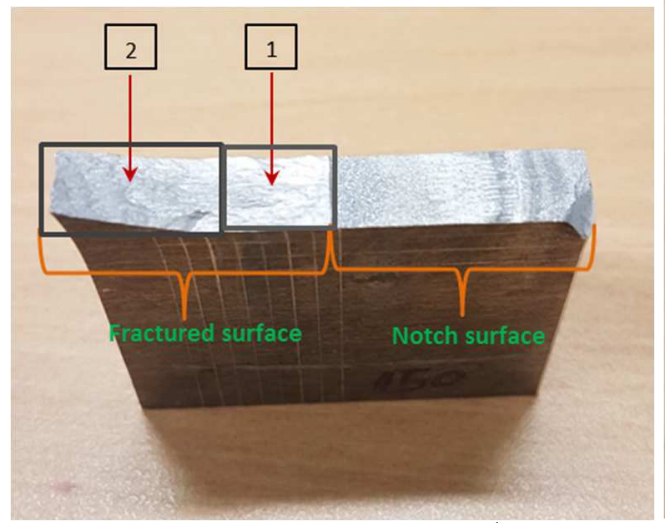

(a) AA2024 - $150 \mathrm{~m} \cdot \mathrm{s}^{-1}$

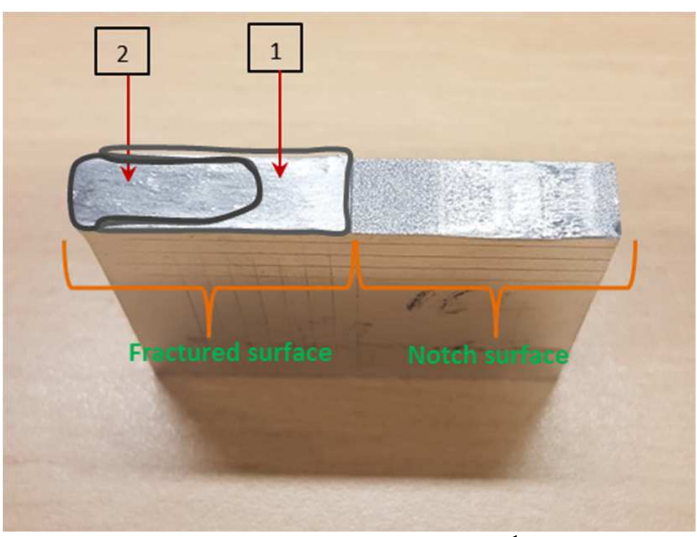

(b) AA7175 - $164 \mathrm{~m} \cdot \mathrm{s}^{-1}$

Fig.28 : Fractography of ruptured surface (a) AA2024 at impact speed of $150 \mathrm{~m} \cdot \mathrm{s}^{-1}$ (b) AA7175 at impact speed of $164 \mathrm{~m} \cdot \mathrm{s}^{-1}$

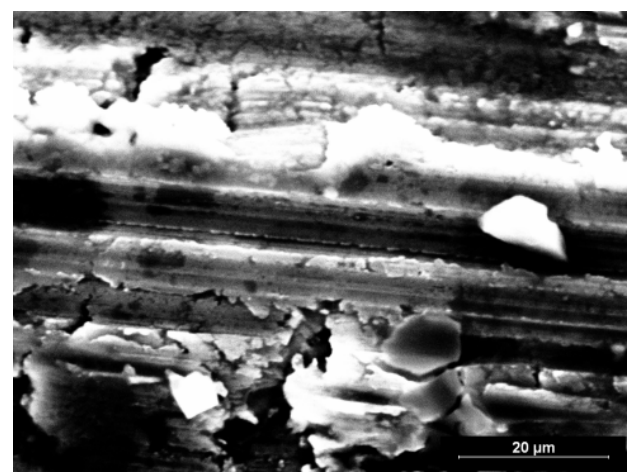

(a) Zone 1

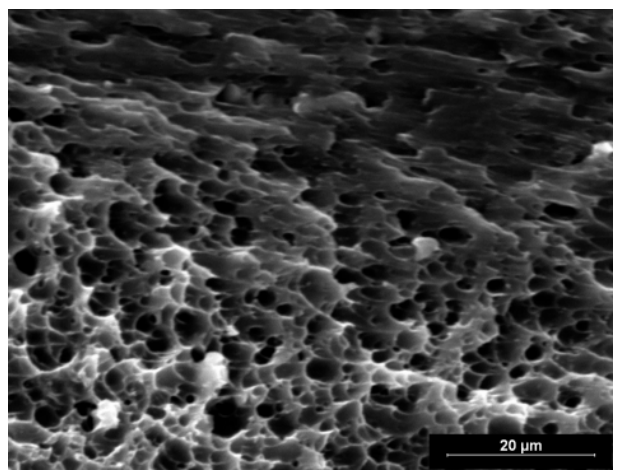

(b) Zone 2

Fig.29 : Microstructural view of AA2024 at fractured surface after impact at speed of $150 \mathrm{~m} . \mathrm{s}^{-1}$

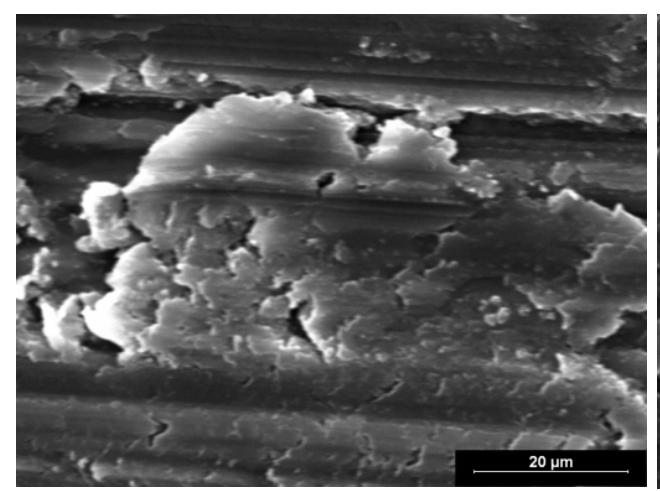

(a) Zone 1

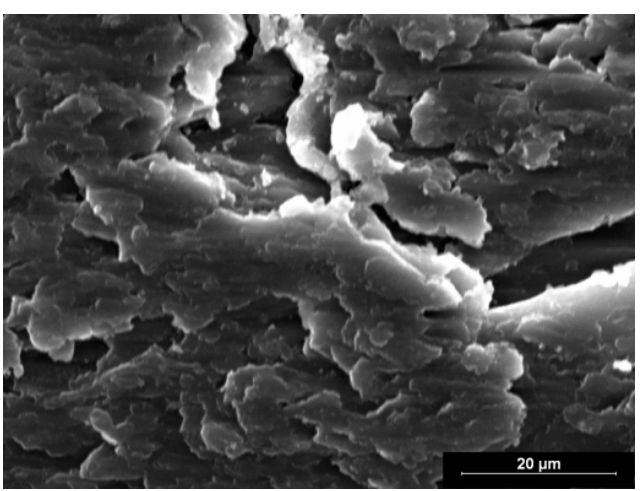

(b) Zone 2

Fig.30 : Microstructural view of AA7175 at fractured surface at speed of $164 \mathrm{~m} \cdot \mathrm{s}^{-1}$ (a) Flat shear (b) Flat shear

Fig.31(a) and (b) shows the ruptured surface of specimen after impact at the speed of 222 $\mathrm{m} . \mathrm{s}^{-1}$ for AA2024 and $230 \mathrm{~m} . \mathrm{s}^{-1}$ for AA7175.

\section{Analysis on AA2024}

According to Fig.31 (a) two different fractured zones can be seen. Zone 1 shows the surface at crack initiation and zone 2 shows the crack propagation which leads to full fracture of the structure. 


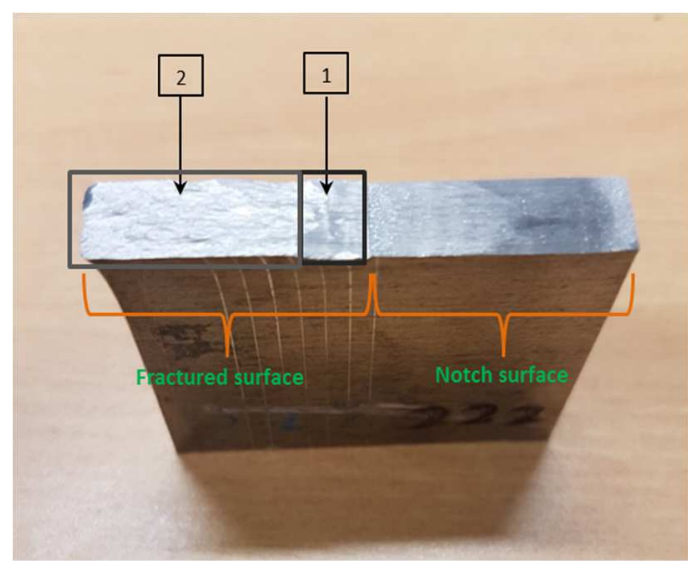

(a)

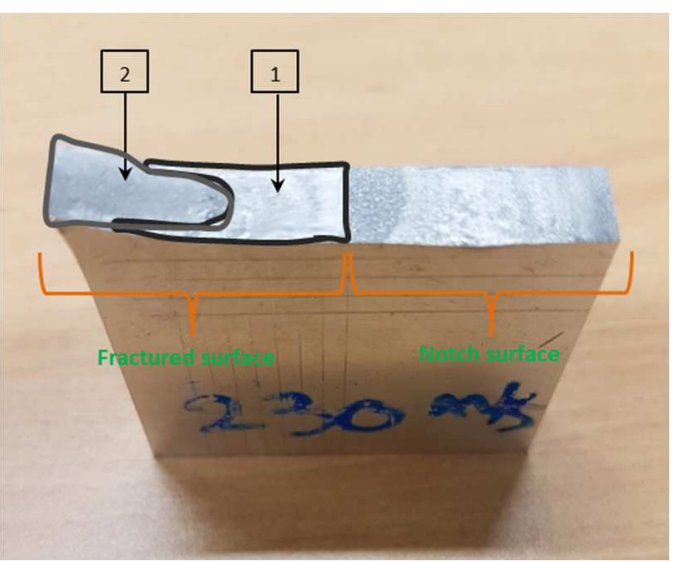

(b)

Fig.31 : Fractography of ruptured surface (a) AA2024 at impact speed of $222 \mathrm{~m} . \mathrm{s}^{-1}$ (b) AA7175 at impact speed of $230 \mathrm{~m} \cdot \mathrm{s}^{-1}$

Fig.32 shows the microstructure of AA2024 for both zones of ruptures. Microstructural view for AA2024 shows, first zone is flat shear (Mode II) and second zone is opening mode where microstructural view shows a dimple cluster (Mode I) for AA2024.

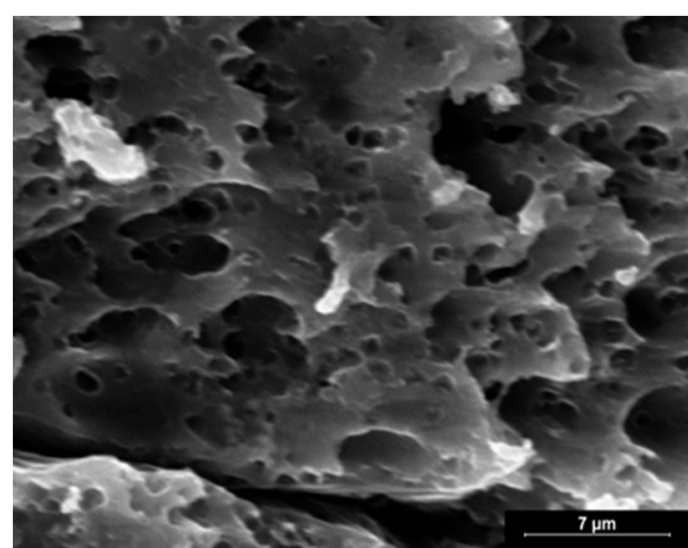

(a)

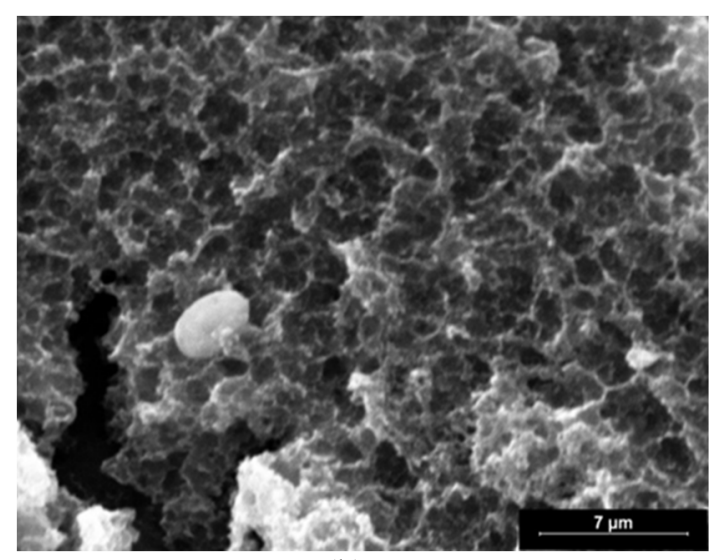

(b)

Fig.32 Microstructure view of AA2024 at ruptured surface (a) Flat shear (b) Dimple cluster

\section{Analysis on AA7175}

Fig.31 (b) also shows two zones where, zone 1 is crack initiation and zone 2 is crack propagation lead to full fracture of the structure. According to Fig.31(b) crack lip area depicts similarity with the crack initiation zone 1 . It is to be noted that this similarity is also observed for AA 7175 at impacted speed of $164 \mathrm{~m} \cdot \mathrm{s}^{-1}$.

Fig.33 shows the microstructure of AA7175 after impact at speed of $230 \mathrm{~m} . \mathrm{s}^{-1}$. Microstructural view of AA7175 shows both region are flat shear surface, thus the failure is once again mainly due to shear (Mode II).

For AA2024, there are evidences of zones of failures under Mode II and Mode I. For AA7175, there are evidences of zones of failures under Mode II only. 


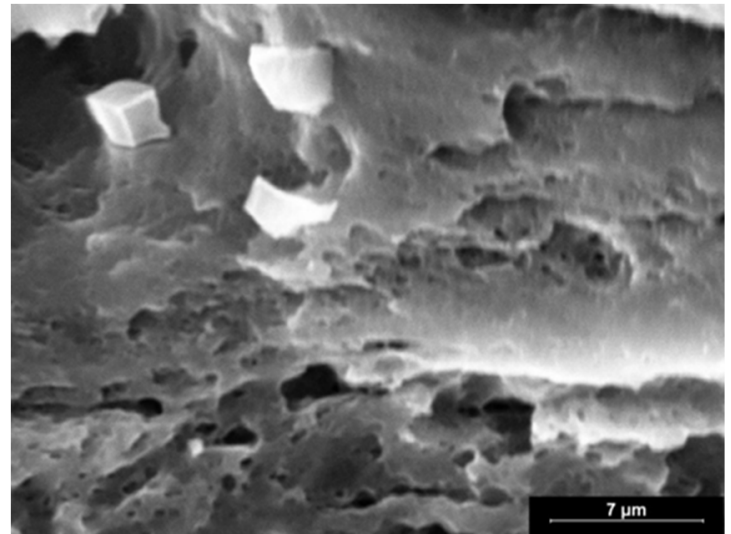

(a)

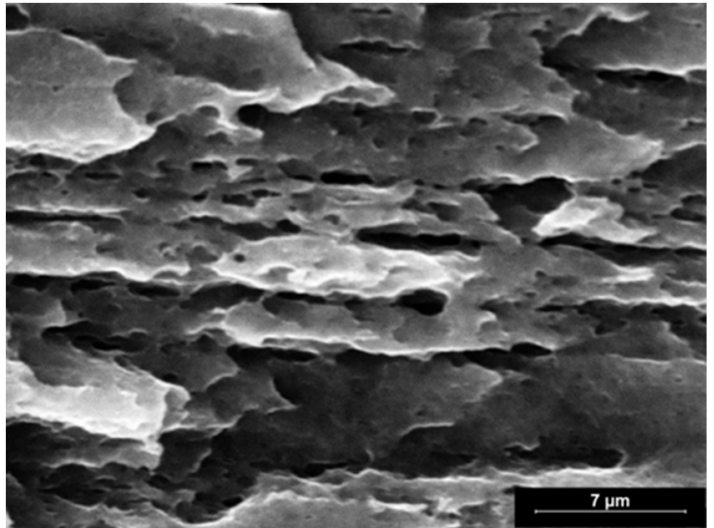

(b)

Fig.33 : Microstructure view of AA7175 at ruptured surface (a) Flat shear (b) Flat shear

\subsubsection{Crack lips analysis}

Specimens were polished and etched near the crack lip by acid (M4) in order to observe the microstructure near crack lip, see Fig.34.

For AA2024 crack lip analysis does not show any evidence of shear band see Fig.35, and on the other hand for AA7175 the adiabatic shear band with average width of $6 \mu \mathrm{m}$ is visible on the crack lips as shown in Fig.36.

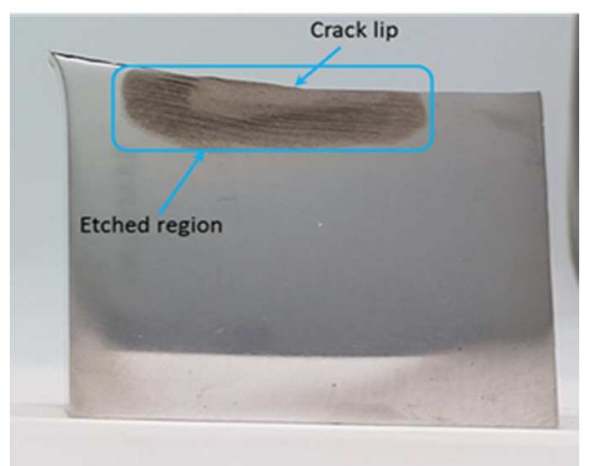

(a) AA2024

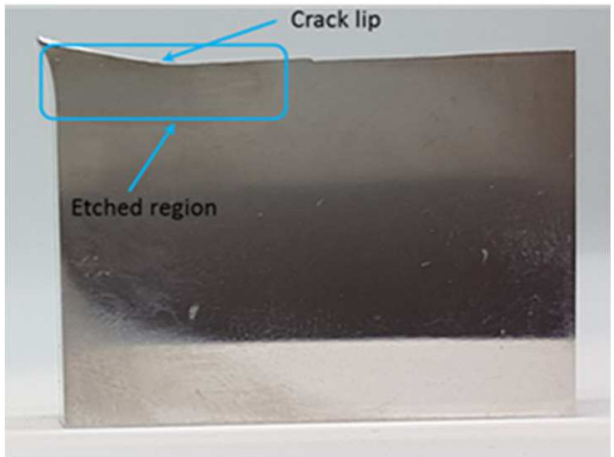

(b) AA 7175

Fig.34 : Specimens of AA2024 and AA7175 after polishing and etching

\subsection{Nano-hardness of crack tip surface}

Nano-hardness on the surface near the crack tip region was done by using nano-indentor apparatus as discussed earlier in the subsection 3.2.5. Total area of the indentation is a $2 \times 2$ $\mathrm{mm}^{2}$-square. The region around the crack tip is expected to be the siege of microstructural transformations which may be revealed by the nano-hardness tests.

\section{Analysis on AA2024}

Figs.37 and 38 shows the nano-hardness at crack tip for AA 2024 after impact speeds of 111 and $133 \mathrm{~m} . \mathrm{s}^{-1}$ respectively. 

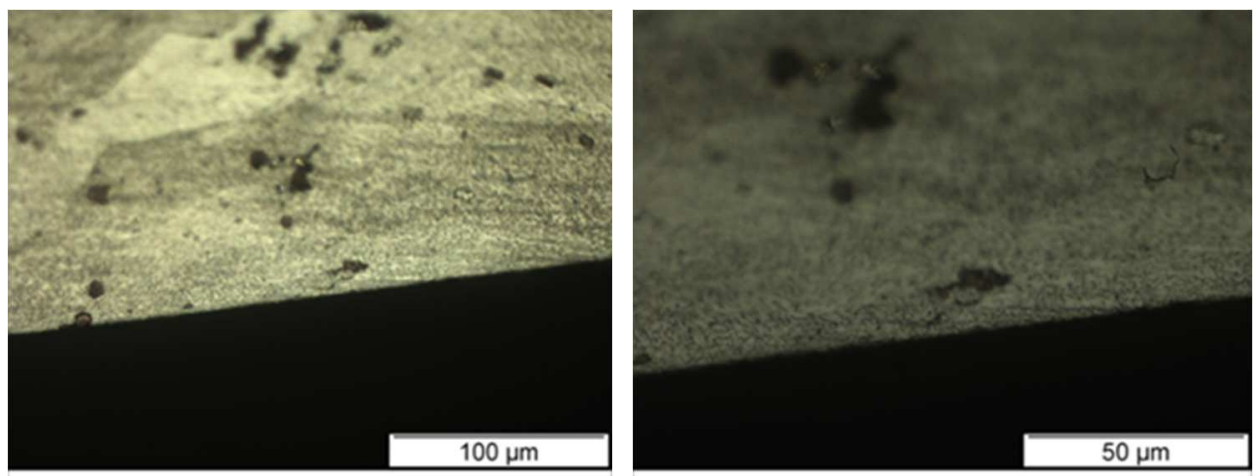

Fig.35 : Optical microscopic view of crack lip region for AA2024
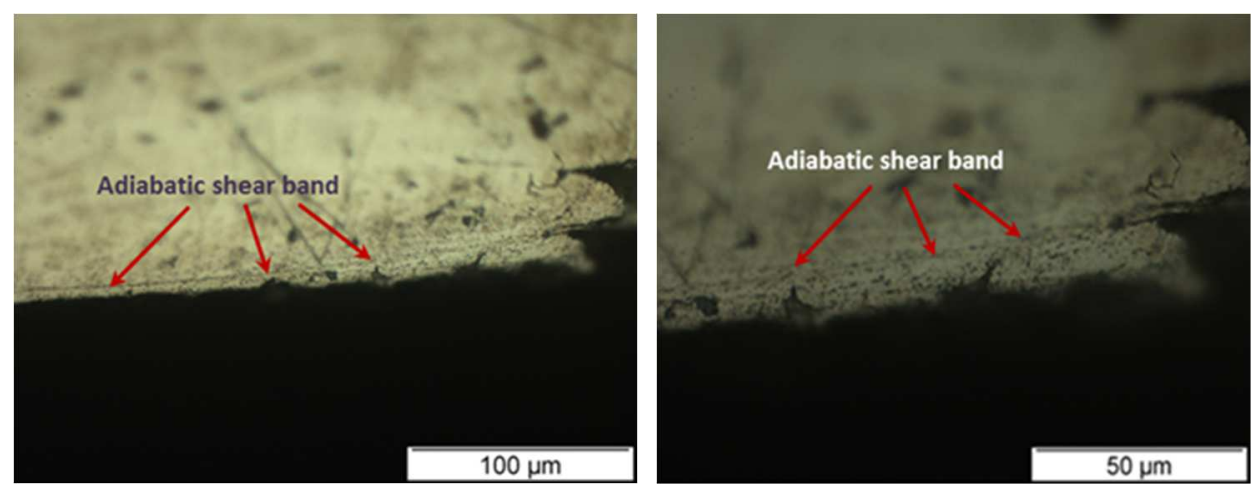

Fig.36 : Optical microscopic view of crack lip region for AA7175
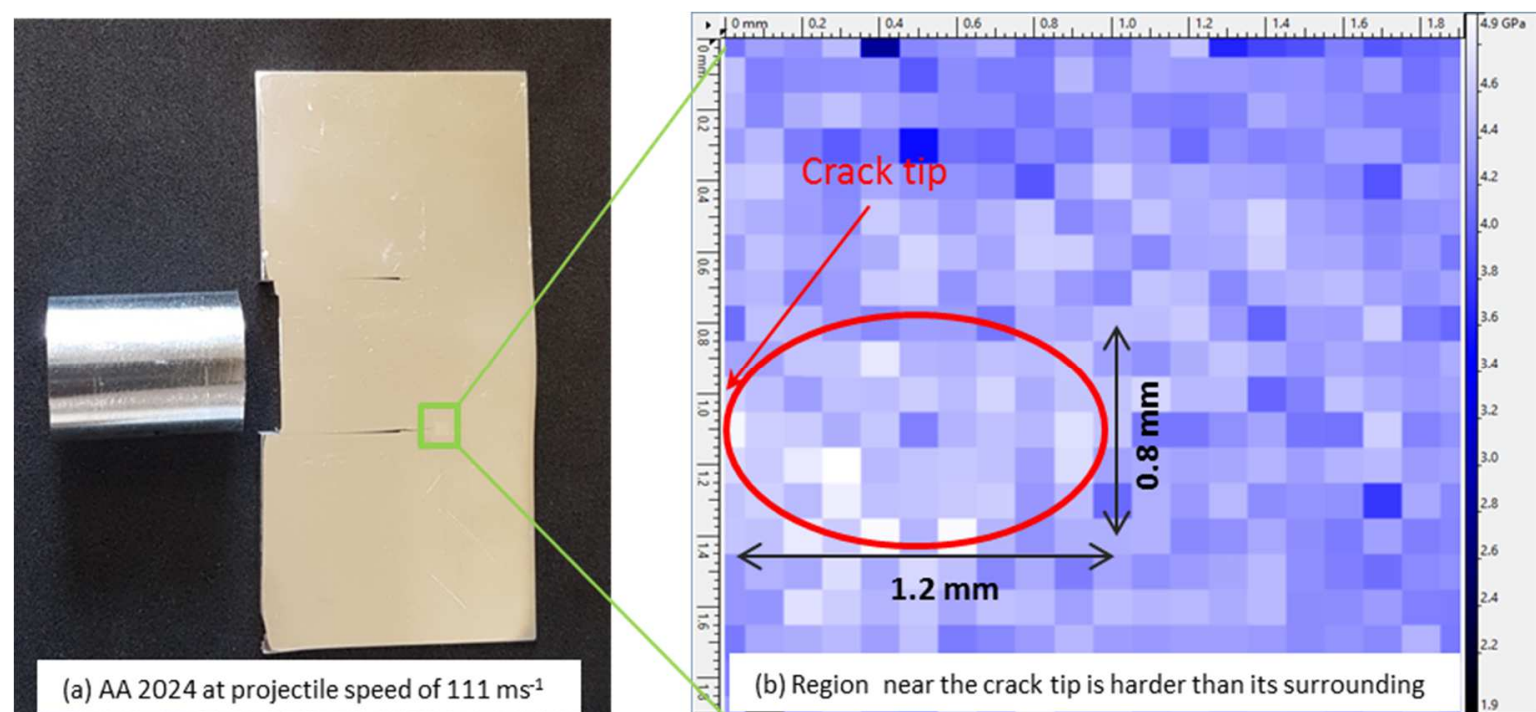

Fig. 37 : Nanohardness of crack tip for AA 2024 at impacted speed of $111 \mathrm{~m} . \mathrm{s}^{-1}$. Light blue for higher hardness value and dark blue for lower hardness value.

According to Figs.37-38, the region around lower part crack tip shows that nano-hardness is higher near the crack tip (crack process zone) compared to its surrounding regions as depicted in Fig.37(b) where the white shows harder area and the dark softer area. The process zone is a wide ellipse. The average value of nano-hardness of crack tip region inside the processing zone is $4.8 \mathrm{GPa}$ whereas average hardness outside the process zone is around 4.5 GPa. The equivalent Vickers hardness (HV) value is given in the table 6 according to Eq.(1).

Fig. 38 shows the specimen and hardness mapping at impact speed of $133 \mathrm{~m} . \mathrm{s}^{-1}$. The region near the crack shows harder than its surrounding area. The average nano-hardness values inside and outside the process zone are 4.6 GPa and 4.0 GPa respectively. 

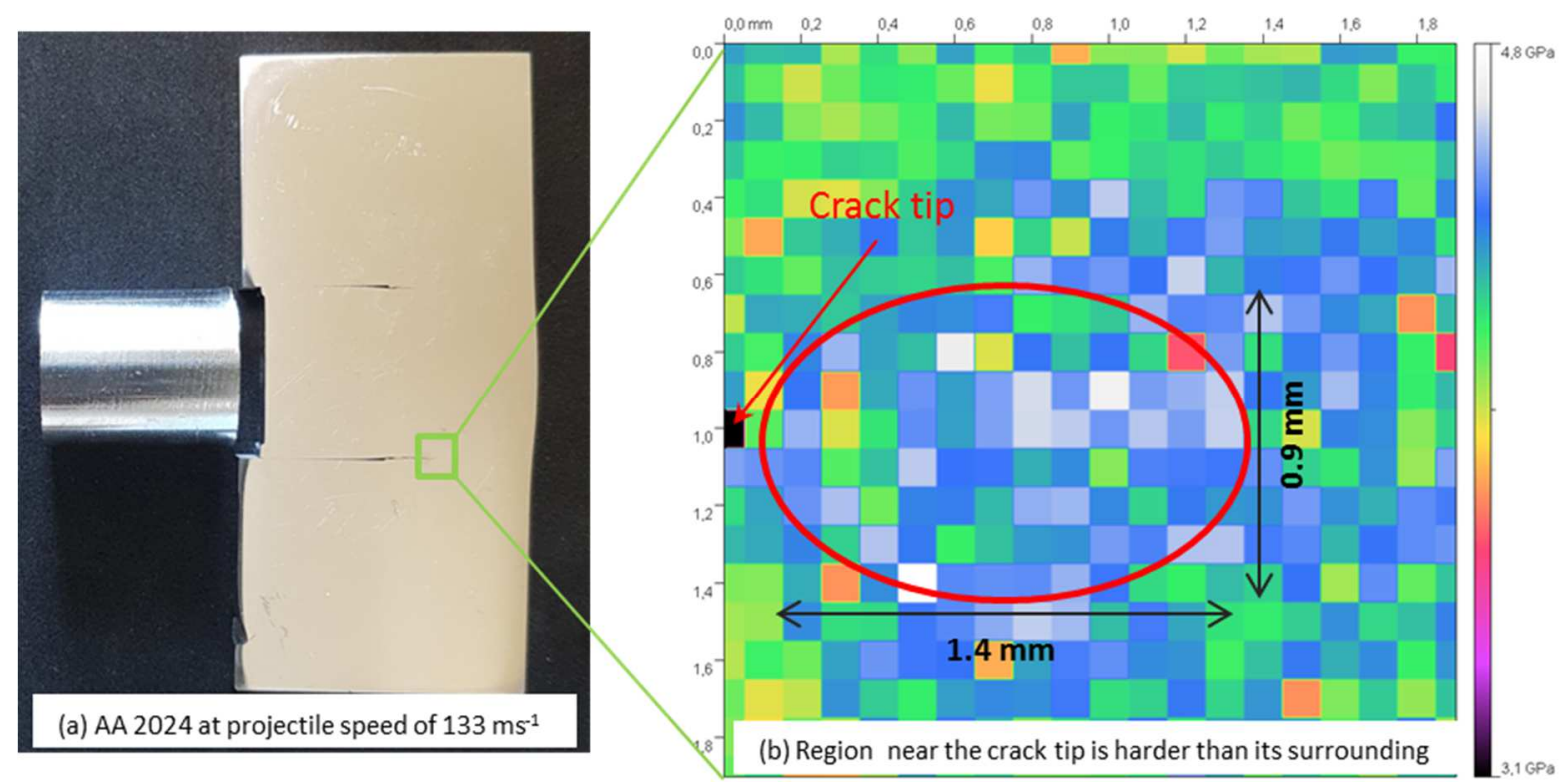

Fig.38 : Nanohardness of crack tip for AA 2024 at impacted speed of $133 \mathrm{~m} . \mathrm{s}^{-1}$. White for higher hardness value and black for lower hardness value.

\section{Analysis on AA7175}

Fig.39 shows nano-hardness mapping for AA7175 after impact speed of $100 \mathrm{~m} . \mathrm{s}^{-1}$. The process zone is a narrow ellipse. The average nano-hardnes inside and outside the processing zone is $4.4 \mathrm{GPa}$ and $4.5 \mathrm{GPa}$ respectively, i.e. a lower hardness inside the process zone and a higher hardness outside.

Fig. 3.40 shows specimen after impact speed of $120 \mathrm{~m} \cdot \mathrm{s}^{-1}$. The process zone is a line of pixels. The crack tip region also shows less hardness inside the process zone compared to its surrounding areas, with 4.2 GPa inside the process zone against $4.4 \mathrm{GPa}$ outside.
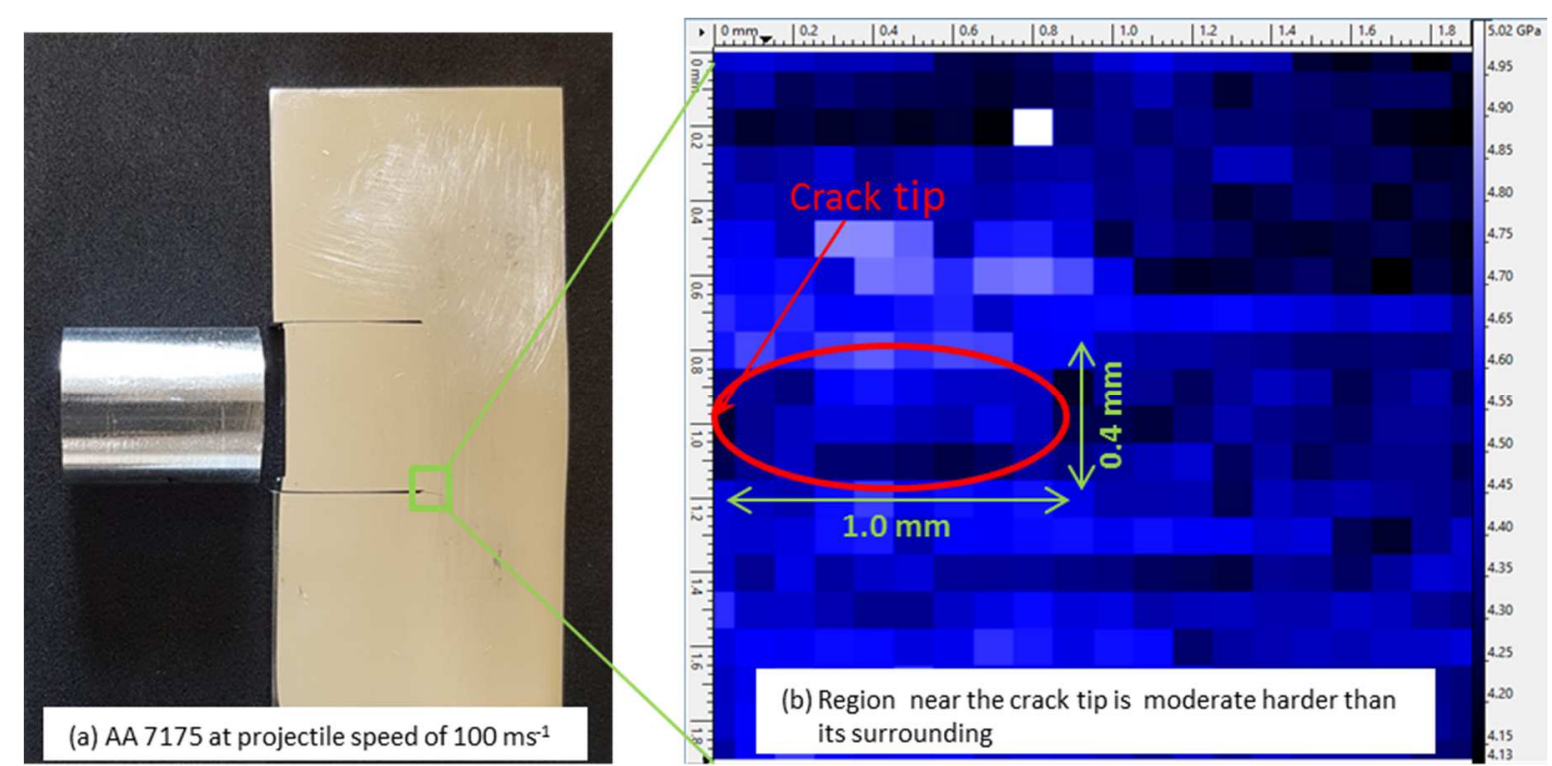

Fig. 39 : Nanohardness of crack tip for AA 7175 at impacted speed of $100 \mathrm{~m}^{-1}{ }^{-1}$. Light blue for higher hardness value and dark blue for lower hardness value. 

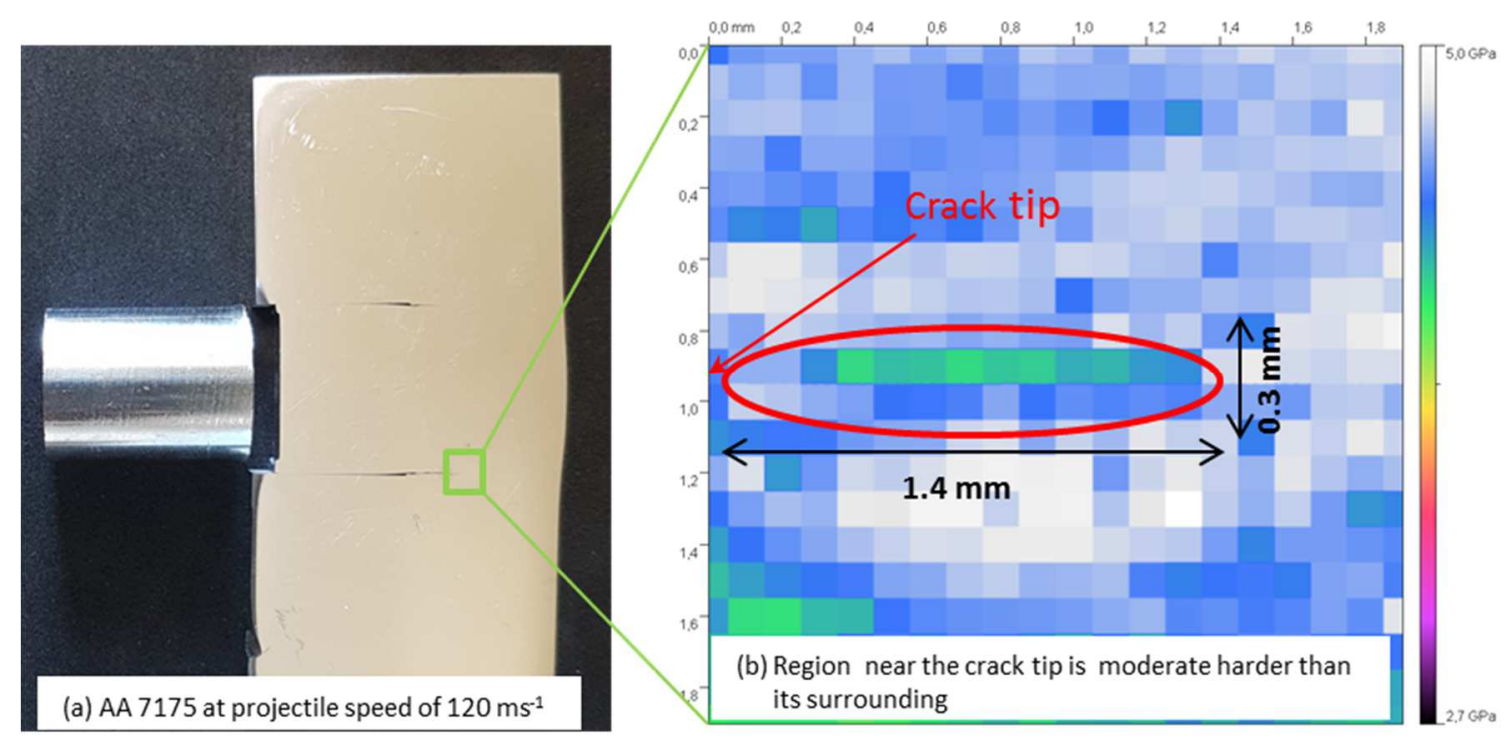

Fig.40 : Nanohardness of crack tip for AA 7175 at impacted speed of $120 \mathrm{~m} . \mathrm{s}^{-1}$. White for higher hardness value and black for lower hardness value.

\section{Summary}

- $\mathrm{AA} 2024$

For AA2024, the critical impact speed for crack arrest inside the structure is close to 150 $\mathrm{m} . \mathrm{s}^{-1}$ Below this critical speed the crack propagates then arrests within the plate. Above this critical impact speed the plate fully fractures into two or three parts as depicted in Fig.11(a).

The crack tip speed was estimated over a time period of $10 \mu$ s for impact speed above critical speed. Maximum value of crack tip speed reaches $980 \mathrm{~m} \cdot \mathrm{s}^{-1}$ for impact speed of 222 $\mathrm{m} \cdot \mathrm{s}^{-1}$.

The crack tip analysis for speed lower than critical impact speed, shows the appearance of (open) macro-crack and (closed, cohesive) meso-crack. Both types of cracks are eventually arrested inside the plate.

Microstructural observation inside the crack for the plates impacted below critical speed shows that the failure is predominantly Mode II induced failure. The microstructure shows at early stage of crack initiation near notch tip is flat shear surface surrounded by elongated dimple cluster. Further crack propagation shows the failure mechanism is under shearing mode due to flat shear surface depicted in this region, see image 2 on Fig.25. Tip of the crack region shows the bifurcation of the crack where the failure mechanism is flat shear surface, see image 3 on Fig. 25.

Fully fractured specimens were analyzed for two different impact speeds, namely 150 and $222 \mathrm{~m} . \mathrm{s}^{-1}$. Both fractured surfaces shows at early stage the failure of the plate under shearing induced Mode II and at latter stage under tension induced Mode I, see Figs.29 and 32.

Crack lip microstructural observation on fully fractured specimen evidences no adiabatic shear bands, see Fig. 35 .

Nano indentation test results prevail that nano-hardness close to crack tip region is larger than surrounding region in the considered process zone for two different specimens analyzed after impact speed of 111 and $133 \mathrm{~m} \cdot \mathrm{s}^{-1}$, see Figs. 37 and 38 respectively. The material in the process zone keeps on being subject to strain hardening without major microstructural changes. 
For AA7175, the critical impact speed to crack arrest inside the plate is close to $130 \mathrm{~m} . \mathrm{s}^{-1}$. Above this critical impact speed the specimen fractures into two or three parts, see Fig.11 (b).

AA7175 shows the formation of a white band which appears in the frames recorded by a high speed camera as the likely optical signature of adiabatic shear banding. The maximum values of the white band and crack tip speeds for the time frame of $10 \mu \mathrm{s}$, was estimated at about $720 \mathrm{~m} . \mathrm{s}^{-1}$ and $800 \mathrm{~m} . \mathrm{s}^{-1}$ respectively for the impact speed of $230 \mathrm{~m} . \mathrm{s}^{-1}$.

The crack tip analysis for speed lower than critical impact speed shows the presence of macro-crack and meso-crack before both cracks eventually arrest inside the specimen.

Microstructural observation inside the crack for the plates impacted below critical impact speed shows that the failure is predominantly Mode II. The microstructure shows flat shear surface along the crack from initiation up to bifurcation zone as depicted in the Fig.27.

Fully fractured specimens were analyzed for two different impact speeds which are above the critical impact speed, namely $164 \mathrm{~ms}^{-1}$ and $230 \mathrm{~ms}^{-1}$. The microstructure for both specimens shows that the fractured was predominant by shearing induced Mode II, see Figs.32 and 33.

Microscopic observations on fully fractured specimen shows that there are bands of shear localization (adiabatic shear bands) with average width of $6 \mu \mathrm{m}$ along the crack lips, see Fig.36.

Nano indentation test results prevail that nano-hardness close to crack tip region is lower than surrounding region in the considered process zone for two different specimen analyzed after impact speeds of 100 and $120 \mathrm{~m} . \mathrm{s}^{-1}$, see Figs.39 and 40 respectively. The material in the process zone is subject to softening caused by major microstructural changes, which is coherent with shear localization upstream from the crack.

- AA2024 vs. AA7175

Critical speed for AA2024 and AA7175 to crack arrest inside the material is close to 150 $\mathrm{m} . \mathrm{s}^{-1}$ and $130 \mathrm{~m} \cdot \mathrm{s}^{-1}$ respectively. The value of the critical impact speed is seen to be higher for AA2024. Crack formation in AA7175 is seen to be preceded by shear localization in the form of adiabatic shear band.

\section{- Below critical speed}

At lower impact speeds both alloys show the presence of (open) macro-crack and (closed) meso-crack. These cracks arrest inside the plate for impact speeds below the critical speed.

Table 5 shows the maximum values of white band and crack tip speed for both alloys. The white band which is likely the optical signature of the shear localization band appears in AA7175 only. The value of its maximum speed is close to $720 \mathrm{~m} . \mathrm{s}^{-1}$. The value of the maximum crack tip speed is higher for AA2024 (980 m.s $\mathrm{s}^{-1}$ against $800 \mathrm{~m} \cdot \mathrm{s}^{-1}$ for AA7175 for the impact configuration considered).

Table 5 : Maximum white band and crack tip speed

\begin{tabular}{|l|c|c|}
\hline Failure & $\begin{array}{l}\text { Maximum white band speed } \\
\left(\mathrm{m}^{-1} \mathrm{~s}^{-1}\right.\end{array}$ & $\begin{array}{l}\text { Maximum crack speed }\left(\mathrm{m} . \mathrm{s}^{-}\right. \\
\left.{ }^{1}\right)\end{array}$ \\
\hline AA 2024 & - & 980 \\
\hline AA 7175 & 720 & 800 \\
\hline
\end{tabular}


Microstructural observation of the inside of the crack for both alloys evidence flat shear surface together with elongated dimple showing that crack initiation is dominated by shearing mode. The crack tip bifurcations of AA2024 and AA7175 are opposite.

\section{- Above critical speed}

Microscopic observation on fully fractured specimens shows for AA2024 that the first stage of fracture is dominated by shearing induced Mode II and that a second stage is dominated by tension induced Mode I. For AA7175 the fracture is controlled by shearing induced Mode II failure only.

The observation on crack lip on fully fractured specimen evidences the absence of shear localization band for AA2024 and the presence of shear localization band for AA7175.

Table 6 shows the averaged value of nano-hardness and its Vickers hardness (HV) equivalent in a region near the crack tip inside and outside the process zone. For AA2024, the area in front of the crack tip is wide and harder, when compared with the surrounding region, see subsection 3.3.4. For AA7175, the area in front of the crack tip is narrow and softer when compared with the surrounding region, see subsection 3.3.4.

Table 6: Average nano-hardness and Vickers hardness inside and outside the process zone

\begin{tabular}{|c|c|c|c|c|c|c|c|c|}
\hline \multirow{4}{*}{ Material } & \multicolumn{4}{|c|}{ AA2024 } & \multicolumn{4}{|c|}{ AA7175 } \\
\hline & \multicolumn{4}{|c|}{ Process zone } & \multicolumn{4}{|c|}{ Process zone } \\
\hline & \multicolumn{2}{|c|}{ Inside } & \multicolumn{2}{|c|}{ Outside } & \multicolumn{2}{|c|}{ Inside } & \multicolumn{2}{|c|}{ Outside } \\
\hline & $\begin{array}{l}\text { Nano- } \\
\text { hardness }\end{array}$ & $\begin{array}{l}\text { Vickers } \\
\text { hardness }\end{array}$ & $\begin{array}{l}\text { Nano- } \\
\text { hardness }\end{array}$ & $\begin{array}{l}\text { Vickers } \\
\text { hardness }\end{array}$ & $\begin{array}{l}\text { Nano- } \\
\text { hardness }\end{array}$ & $\begin{array}{l}\text { Vickers } \\
\text { hardness }\end{array}$ & $\begin{array}{l}\text { Nano- } \\
\text { hardness }\end{array}$ & $\begin{array}{l}\text { Vickers } \\
\text { hardness }\end{array}$ \\
\hline $\operatorname{speed}(\mathrm{m} / \mathrm{s}) \backslash$ & $\mathrm{GPa}$ & $\mathrm{HV}$ & $\mathrm{GPa}$ & $\mathrm{HV}$ & $\mathrm{GPa}$ & $\mathrm{HV}$ & $\mathrm{GPa}$ & $\mathrm{HV}$ \\
\hline 100 & - & & - & & 4.40 & 407 & 4.5 & 416 \\
\hline 111 & 4.8 & 444 & 4.5 & 417 & - & & & \\
\hline 120 & - & & - & & 4.20 & 389 & 4.4 & 407 \\
\hline 133 & 4.60 & 426 & 4.00 & 370 & - & & & \\
\hline
\end{tabular}

\section{Concluding remarks}

In the present work, double notched plates made of AA2024 and AA7175 aluminum alloys were submitted to impact loading in view of experimentally investigating the crack arrest capabilities of the constitutive materials under high strain rate loading in the context of damage tolerance of aeronautical structures. For the impact configurations considered, it is shown that for both alloys there exists a critical impact speed below which cracks, initiated from notch tips, arrest inside the plate and above which cracks propagate throughout the whole plate leading to complete fracture. The critical impact speed is lower for AA7175 which possesses the higher strength, or equivalently higher for AA2024 which possesses the lower strength.

For both alloys the direction of the cracks is initially collinear to the notch direction then follows a slight angle so as the cracks would converge if the plate were infinitely wide, evidencing a crack propagation under predominant shear controlled Mode II. Bands of shear localization are observed on the crack lips of post-impacted AA7175 plates and not on the ones of post-impacted AA2024 plates. Adiabatic shear bands are known to favor premature failure. Adiabatic shear banding may explain the low value of critical impact speed for AA7175 when compared with the impact speed for AA2024. Moreover, crack propagation 
according to Mode II (i.e. following a slight angle) is not necessarily preceded by adiabatic shear banding. Yet, if so, it would lead to a premature failure. Microscopic analyses of the crack surfaces reveal ductile fracture for both materials.

A crack bifurcation is observed for arrested cracks, i.e. for impact speed lower than critical speed. The analysis of wave interactions during the impact-induced loading shows that the plate and the cracks are subject to complex, alternate shear and tension loading. The crack bifurcation may thus more probably result from the turn of predominant shear wave-induced loading to predominant tension wave-induced loading, as a consequence of changes in the loading path and not as a consequence of changes in the failure micro-mechanisms (e.g ductile to brittle).

These experimental results may be used to discriminate numerical models aiming at reproducing the failure of lightweight alloys under impact loading within an engineering design process. Indeed, designers can use the data provided in the present work for verifying new approaches in the context of verification and validation $(\mathrm{V} \& \mathrm{~V})$ procedures, i.e. as an intermediate step between the first step of material constant calibration and the ultimate step of verification of the numerical model.

\section{Acknowledgment}

The authors would like to acknowledge the contributions of V. Godivier for assisting on usage of optical microscope and SEM; T. Martin and C.M. Sanchez for assisting in conducting nano-hardness test; O. Cherrier and A. Chardonneau, for assisting in conducting gas launcher impact tests.

\section{References}

[1] J. F. Kalthoff and S. Winkler, "Failure mode transition at high rates of shear loading in: C.Y. Chiem, H.-D. Kunze,L.W.Meyer(Eds.)," Proc. Int. Conf. Impact Load. Dyn. Behav. Mater., vol. 1, pp. 185-195, 1987.

[2] J. F. Kalthoff and A. Bürgel, "Influence of loading rate on shear fracture toughness for failure mode transition," Int. J. Impact Eng., vol. 30, no. 8-9, pp. 957-971, 2004.

[3] E. Roux, P. Longère, O. Cherrier, T. Millot, D. Capdeville, and J. Petit, "Analysis of ASB assisted failure in a high strength steel under high loading rate," Mater. Des., vol. 75, pp. 149-159, 2015.

[4] M. Zhou, A. J. Rosakis, and G. Ravichandran, "Dynamically propagating shear bands in impact-loaded prenotched plates-I. Experimental investigations of temperature signatures and propagation speed," J. Mech. Phys. Solids, vol. 44, no. 6, pp. 981-1006, 1996.

[5] P. Longère and A. Dragon, "Dynamic vs. quasi-static shear failure of high strength metallic alloys: Experimental issues," Mech. Mater., vol. 80, no. PB, pp. 203-218, 2015.

[6] Y. B. Bradley Dodd, Introduction to Adiabatic shear localization, Revised Ed. Imperial College Press, 2015.

[7] P. Longère, "Adiabatic shear banding assisted dynamic failure: Some modeling issues," Mech. Mater., vol. 116, pp. 49-66, 2018.

[8] C. Zener and J. H. Hollomon, "Effect of strain rate upon plastic flow of steel," J. Appl. Phys., vol. 15, no. 1, pp. 22-32, 1944.

[9] J. Dormeval, Richard \& Pierre Ansart, "Adiabatic Shearing: Influence of 
Predeformation.. Journal de Physique (Paris), Colloque. 46. 299-306.,” J. Phys. Paris), vol. 46, pp. 299-306, 1985.

[10] A. Marchand and J. Duffy, "an Experimental-Study of the Formation Process of Adiabatic Shear Bands in a Structural-Steel," J. Mech. Phys. Solids, vol. 36, no. 3, p. 251-, 1988.

[11] C. Mazeau, L. Beylat, P. Longere, and P. F. Louvigne, "On the quantitative evaluation of adiabatic shear banding sensitivity of various titanium alloys," J. Phys. IV JP, vol. 7, pp. 429-434, 1997.

[12] S. -C. Liao and J. Duffy, "Adiabatic shear bands in a Ti-6Al-4V titanium alloy," J.Mech.Phys.Solids, vol. 46, no. 11, pp. 2201-2231, 1998.

[13] Z. guo Gao, X. ming Zhang, Y. sheng Zhao, M. an Chen, and H. jie Li, "The effect of strain rate on the microstructure of 2519A aluminium alloy plate impacted at $573 \mathrm{~K}$," $J$. Alloys Compd., vol. 481, no. 1-2, pp. 422-426, 2009.

[14] X. P. Liang, H. Z. Li, L. Huang, T. Hong, B. Ma, and Y. Liu, "Microstructural evolution of 2519-T87 aluminum alloy obliquely impacted by projectile with speed of 816 m/s," Trans. Nonferrous Met. Soc. China (English Ed., vol. 22, no. 6, pp. 12701279, 2012.

[15] Y. Yang, Y. Zeng, and Z. W. Gao, "Numerical and experimental studies of selforganization of shear bands in 7075 aluminium alloy," Mater. Sci. Eng. A, vol. 496, no. 1-2, pp. 291-302, 2008.

[16] Y. Yang, D. H. Li, H. G. Zheng, X. M. Li, and F. Jiang, "Self-organization behaviors of shear bands in 7075 T73 and annealed aluminum alloy," Mater. Sci. Eng. A, vol. 527, no. 1-2, pp. 344-354, 2009.

[17] C. Mondal, B. Mishra, P. K. Jena, K. Siva Kumar, and T. B. Bhat, "Effect of heat treatment on the behavior of an AA7055 aluminum alloy during ballistic impact," Int. J. Impact Eng., vol. 38, no. 8-9, pp. 745-754, 2011.

[18] Starke E.A. Jr and Staley J.T., "Application of modern aluminum alloys to aircraft," Pergamon, vol. 32, pp. 131-172, 1996.

[19] T. Dursun and C. Soutis, "Recent developments in advanced aircraft aluminium alloys," Mater. Des., vol. 56, pp. 862-871, 2014.

[20] I. El-Mahallawi, M.M.Z. Ahmed, A.A. Mahdy, A.M.M. Abdelmotagaly, W. Hoziefa and M. Refat, "Effect of heat treatment on friction-stir-processed nanodispersed AA7075 and 2024 Al alloys", [in] Friction Stir Welding and Processing IX, Eds. Y. Hovanski, R. Mishra, Y. Sato, P. Upadhyay and D. Yan, Springer, pp.297-310, 2017 